\title{
El ciudadano como núcleo esencial del Derecho Administrativo
}

\author{
Miren Sarasíbar Iriarte \\ Profesora Contratada Doctora (Titular acreditada) de \\ Derecho Administrativo. Universidad Pública de Navarra
}

"Hominis causa omne ius constitutum est"
"El Derecho está al servicio de las personas"

SUMARIO:

EL ADMINISTRADO O CIUDADANO GOMO PUNTO DE PARTIDA EN EL DERECHO ADMINISTRATIVO. 1. Concepto de administrado: el protagonista del Derecho Administrativo. 2. El administrado como sujeto merecedor de protección. 3. El concepto de ciudadanía como buena administración en el ámbito comunitario. 4. El principio de buena administración en el ámbito español. II. LA EVOLUCIÓN DEL DERECHO ADMINISTRATIVO: DEL DEREGHO DEL PODER AL DEREGHO DE LA PERSONA A UNA BUENA ADMINISTRACIÓN. 1. El incremento del protagonismo de la sociedad. 2. La nueva realidad del Estado garante. III. EN BÚSQUEDA DEL EQUILIBRIO: LAS NEGESARIAS GARANTÍAS DEL ADMINISTRADO RESPEGTO DE LA ADMINISTRACIÓN. 1. Conceptos de deber, derecho subjetivo y sujeción. 2. Concepto de garantía como salvaguarda frente a la Administración. 3. El derecho de defensa como garantía del particular ante la Administración. 4. El procedimiento administrativo como deber de la Administración y como garantía de defensa para las personas. 5. El silencio administrativo: ¿una garantía para las personas?. 6. El principio de confianza legítima como garantía de igualdad. IV. REFLEXIÓN FINAL. V. BIBLIOGRAFÍA.

\section{RESUMEN:}

El artículo trata sobre la posición que ocupa el ciudadano ante la Administración y las garantías que tiene frente a la misma. Se enfatiza la importancia de tal figura puesto que constituye el fundamento de la actuación de la Administración pública. Sin él, la actuación de la Administración carece de sentido. Por ello, el Derecho Administrativo ha evolucionado de ser un Derecho del poder a ser un Derecho del 
ciudadano a una buena administración. Asimismo, el Estado es un Estado garante, un Estado que se preocupa porque los servicios gestionados por los particulares se realicen de forma correcta. Por último, se hace referencia a una serie de garantías que el ciudadano tiene frente a la Administración pero que con la nueva Ley de Procedimiento y la nueva Ley del Sector Público se ha desaprovechado la oportunidad de realzarlos y de conceder mayor importancia a la figura y derechos del ciudadano.

PALABRAS GLAVE:

Ciudadano, garantía, buena administración, Estado garante

ABSTRACT:

The article deals with the position that the citizen in the face of the Administration and the guarantees that it has. The value of such a figure is emphasized since it constitutes the basis of the performance of the public administration. Without it, the administration's actions are meaningless. For this reason, Administrative Law has evolved from being a right of power to being a citizen's right to a good administration. Likewise, the State is a guarantee State, a State that is concerned that the services managed by individuals are carried out correctly. Finally, reference is made to a series of guarantees that the citizen has in the face of the Administration, but with the new Law of Procedure and the new Public Sector Law, has lost the opportunity to enhance them and to give greater importance to the figure and Rights of the citizen.

KEY WORDS:

Citizen, guarantee, good administration, guarantee State

\section{EL ADMINISTRADO O GIUDADANO COMO PUNTO DE PARTIDA EN EL DEREGHO ADMINISTRATIVO.}

\section{Concepto de administrado: el protagonista del Derecho Administrativo.}

El concepto de "administrado" parece a simple vista un término que no induce a algo importante. Es decir, es un sujeto que se configura como la parte pasiva de una relación de dos en el que el sujeto importante es la Administración. La Administración ocupa un lugar principal y relevante quedando relegado el administrado a ser el destinatario de la actuación de la Administración.

Sin embargo, esto no debe ser la concepción real del término "administrado" ya que sin él, la actuación de la Administración carece por completo de sentido. Sin la existencia de un sujeto al que la Administración pueda enfocar o dirigir sus medidas, la Administración como poder público se desvanece. Es más, recordando 
la finalidad de cualquier actuación administrativa, que es la persecución del interés público, es decir, el interés del mayor número de población, la figura del administrado es simplemente esencial. Y esto debe ser recordado siempre.

La segunda idea que quiero dejar clara es que no sólo el administrado es el que fundamenta y justifica la actuación de la Administración sino que es el administrado el sujeto que ostenta una serie de derechos y garantías que tiene que salvaguardar respecto de la Administración, tal como se verá más adelante. En palabras de GONZÁLEZ PÉREZ, "a fuerza de hablar de prerrogativas, de poderes exorbitantes, del interés público, de los servicios públicos, de la planificación, del desarrollo económico, uno llega a olvidarse que el fundamento y razón de ser de esa ingente actividad administrativa, como el fundamento y razón de ser del Estado mismo, no es otro, en definitiva que el hombre, su bienestar, hacer que su paso por la tierra sea más agradable, mejor"'.

El Estado de Derecho sólo tiene sentido si situamos al sujeto, a la persona, como centro y fundamento de todo el Derecho. Y se entiende por Derecho al conjunto de relaciones de exigibilidad personal para la protección de la integridad de la dignidad personal. El Estado y, en consecuencia, la Administración, está al servicio del ciudadano, esa es su función. Sobre el individuo tiene que rotar toda la estructura administrativa de poder que supone la Administración como poder público. Si la Administración pierde de vista al sujeto como destinatario de todas sus actuaciones, el Estado de Derecho se destruye. El Estado es el defensor y garante de los derechos del ciudadano.

El administrado ha de estar investido de unas garantías mínimas que constituyen la salvaguardia de la esfera de la libertad individual, que es la esencia de un Estado que de verdad sea un Estado de Derecho.

Y obviamente, la vinculación positiva al Derecho es innato al poder público. La Administración está obligada a cumplir y respetar la ley y el Derecho ya que todas las medidas y actuaciones que realice son creadas por el Derecho y la legitimidad de las mismas depende de que el Derecho se lo permita ${ }^{2}$. El cumplimiento del principio de legalidad por parte de la Administración supone también una garantía esencial para el administrado ya que supone el respeto a la ley y a la norma y sumisión de los órganos del Estado y demás entes públicos a un orden jerárquico de normas.

\footnotetext{
GONZÁLEZ PEREZ, J., "El administrado", Revista Crítica de Derecho Inmobiliario, 452, 1966, p.
10. Este autor enfatiza el poco reconocimiento que se le da a la figura del administrado en los manuales y tratados de Derecho Administrativo, idea con la que estoy totalmente de acuerdo cuando es el administrado el centro del sistema, el fundamento del mismo.

2 MARTÍNEZ LÓPEZ-MUÑIZ, J. L., "La garantía constitucional del Derecho Administrativo", en el vol. col. BALADO, M. y GARCÍA REGUERO, J. A., La Constitución Española de 1978 en su XXV aniversario, ed. Bosch, Madrid, 2003, pp. 17-27.
} 
Sin embargo, en palabras de SÁNCHEZ BLANCO, el administrado no ha sido el "centro del sistema, al observar que no se le reconoce ni la entidad de un título, un capítulo o una sección en los libros, tratados o manuales de Derecho Administrativo, donde todo lo más se le dedica es un epígrafe o apartado como elemento de la relación jurídico-administrativa, naturalmente predeterminada por los privilegios de la Administración pública”3.

El concepto de administrado o ciudadano radica de la distinción entre lo político y lo administrativo, entre lo que entendemos por gobernar y por administrar. El Estado ha sido durante siglos casi exclusivamente una organización del Derecho y de la Autoridad, una estructura de límites y condicionamientos jurídicos, dentro de los cuales la actividad positiva y encaminada a promover directamente el bienestar del país estaba en manos del sector privado, por lo que el Estado apenas "administraba".

Parece que el término de administrado obedece, a mi juicio, al sujeto como destinatario de una concreta actuación por parte de la Administración, ocupando en cierta medida una actitud pasiva. Sin embargo, el término de ciudadano tiene mayor peso en el sentido que es un sujeto que tiene una actitud de exigencia respecto de la Administración, un sujeto que reivindica sus derechos y su posición jurídica frente a la Administración y, en consecuencia, ocupa una actitud activa, participando de la esfera pública. En palabras de FÉLIX MONTIEL, "de lo que se trata es de plantear si el administrado puede encontrarse frente a las instituciones administrativas en una posición análoga a la del ciudadano con relación a las instituciones políticas" ${ }^{5}$.

\section{El administrado como sujeto merecedor de protección.}

Con el reconocimiento de derechos fundamentales por parte de la Constitución y de la acción pública, la condición del administrado se fortalece ya que le sitúa como sujeto protegido por la legislación y con herramientas para defender sus derechos ante el poder público. Por ello, el Derecho Administrativo debe proteger los derechos de los individuos frente a la Administración y poner a disposición de ésta los procedimientos e instrumentos jurídicos que le permitan un cumplimiento eficaz de sus

SÁNCHEZ BLANCO, A., "Del supraconcepto de administrado a la concreción constitucional de colectivos sociales", en el vol. col. MARTÍN-RETORTILLO BAQUER, L. (Coord.), La protección jurídica del ciudadano: (procedimiento administrativo y garantía constitucional): estudios en homenaje al profesor Fesús González Pérez, ed. Civitas, Madrid, 1993, p. 341. 1965, p. 128

FÉLIX MONTIEL, F., "El ciudadano y el administrado", Revista de Administración Pública, 48,

FÉLIX MONTIEL, F., "El ciudadano y el administrado", cit., p. 131. 
funciones. De hecho, como dice MARTÍN REBOLLO, la Administración debe ser una Administración de garantías ${ }^{6}$.

En esta misma línea, ESCRIBANO COLLADO critica que en la LRJ-PAC tampoco existía un precepto en el que de forma expresa se reconozca el derecho de defensa frente a la Administración, a pesar de que, como dice el autor, sí que en diferentes artículos se regule diversas formas de que los interesados participen en el procedimiento $^{7}$. De hecho, en la propia Ley se establece que si eso no se respeta, el resultado es que el acto resultante es anulable ante la indefensión causada al interesado.

A este respecto, hay autores que establecen que no se produce tal indefensión en el procedimiento administrativo ya que al particular en ese caso le quedaría la vía de los recursos administrativos y jurisdiccionales para poder recurrir tal defecto que le ha ocasionado indefensión. A mi juicio, considero que no debe ser ésta la solución que debe imperar, sino que en el procedimiento se deben garantizar siempre los derechos y garantías del administrado y que sólo como medida residual, debe contemplarse la opción de los recursos. En otro caso, no estaríamos respetando el abanico de garantías que el administrado debe tener y los recursos se convertirían en el medio de garantía y no, en otro instrumento más, como es en la actualidad. Por ello, surge la pregunta de si realmente se reconoce un derecho de defensa del ciudadano frente a la Administración.

El término indefensión está íntimamente ligado al artículo 24.1 de la Constitución ya que la vulneración del derecho fundamental a la tutela judicial efectiva produce tal indefensión. Sin embargo, este artículo sólo se ciñe a cuando el sujeto afectado por una decisión no tiene posibilidad de defenderse por una mala práctica por parte de los órganos jurisdiccionales.

Tal es el caso de la STS de 5 de diciembre de $2014^{8}$, en la que se argumenta que en relación con la calificación de un examen, el hecho de "se han infringido las reglas que deben regir el proceso contencioso-administrativo pues sosteniendo un error por parte del Tribunal Calificador en la cuantificación de los errores mecanográficos, habiendo aportado copia del examen que realizó y solicitado prueba pericial, ésta es denegada, sin que su realización sea impertinente. En efecto sobre este mismo proceso selectivo ha recaído sentencia de esta Sala de 10 de septiembre de 2014, donde se

\footnotetext{
MARTÍN REBOLLO, L., "La Administración de garantías: vigencia y limitaciones", Revista del Centro de Estudios Constitucionales, 13, 1992, pp. 31-54.

ESCRIBANO COLLADO, P., "Reflexiones sobre la indefensión en el procedimiento administrativo", en el vol. col. MARTÍN-RETORTILLO BAQUER, L. (Coord.), La protección jurídica del ciudadano: (procedimiento administrativo y garantía constitucional): estudios en homenaje al profesor Fesús González Pérez, ed. Civitas, Madrid, 1993, p. 537.

$8 \quad$ RJ 2014\6365.
} 
admitió la pretensión de la recurrente, precisamente en virtud de la prueba pericial practicada, por lo que efectivamente a la recurrente se le ha producido indefensión, al no admitir dicha prueba, único modo de probar el error del Tribunal Calificador, y en consecuencia procede admitir el motivo, y por ello el recurso de casación”.

Lo mismo ocurre con la STS de 3 de julio de $2015^{9}$, en la que se establece que "la Administración actuante no le ha conferido intervención alguna en el procedimiento sobre la autorización ambiental concedida a Ercros Industrial SA, omitiendo su condición de interesada por razón del repetido vertido que le afecta directamente. Por ello alega que se le ha causado indefensión y perjuicio irreparable a sus derechos e intereses, que deben ser tutelados. En definitiva, la actora alega que la actuación administrativa objeto del presente proceso modifica derechos subjetivos de los que es titular prescindiendo total y absolutamente del procedimiento legalmente establecido, esto es, la revisión anticipada de su autorización ambiental... la concurrencia de vida de hecho y desviación de poder, además de la falta de trámite de audiencia en el expediente administrativo y de haberse prescindido del procedimiento legalmente establecido, por lo que pretende la nulidad de pleno derecho de las resoluciones y autorización ambiental recurridas...La Sala de instancia constata en su siguiente FD $3^{\circ}$ la inexistencia de práctica del trámite de audiencia respecto de la entidad recurrente (Inquide) en el procedimiento tramitado para el otorgamiento de autorización ambiental".

El Tribunal cita otros pronunciamientos relacionados con el tema de la sentencia como es el caso de la STS de 11 de julio de $2003^{10}$, que resume en lo sustancial la doctrina de este Tribunal en materia de nulidad de actos administrativos derivada de la falta de cumplimiento del trámite de audiencia en un procedimiento no sancionador ya que en dicha sentencia se afirma que tal falta de audiencia no es, por si propia, causa de nulidad de pleno derecho, sino que sólo puede conducir a la anulación del acto en aquellos casos en los que tal omisión haya producido la indefensión material y efectiva del afectado por la actuación administrativa. Por otra parte, tal como establece la STS de 13 de octubre de $2000^{11}$, la falta de un trámite como el de audiencia, por esencial que pueda reputarse, no supone por sí misma que se haya prescindido total y absolutamente del procedimiento legalmente establecido que puede subsistir aun faltando la decisiva audiencia del interesado, por lo que tampoco le afecta, en principio, la causa de nulidad de pleno derecho prevista en la letra e) del artículo 62 de la Ley 30/1992 (en adelante, LRJPAC).

\footnotetext{
RJ $2015 \backslash 3454$.

$10 \quad$ RJ $2003 \backslash 5433$.

$11 \quad$ RJ $2000 \backslash 7914$.
} 
De la misma forma, también se refiere a la STS de 12 de diciembre de 2008 dispone que "en efecto, ha de recordarse ante todo que la omisión del trámite de audiencia en procedimientos no sancionadores no constituye en sí misma o por sí sola ninguna de las dos causas de nulidad de pleno derecho previstas en las letras a ) y e) del número 1 del artículo 62 de la LRJPAC, sino que queda regida por la previsión del número 2 del artículo 63 de la misma Ley, de suerte que sólo determinará la anulabilidad del acto dictado en el procedimiento en que se omitió si dio lugar a una indefensión real y efectiva del interesado"12.

Para concluir, el TS en su sentencia de 2015 antes citada, alega que "la imposición de tan drástica consecuencia a una entidad que no ha tenido oportunidad de intervenir en el curso del procedimiento, sin más y sin mayores cautelas, constituye una grave irregularidad procedimental que compromete y repercute negativamente en el ejercicio de sus derechos de defensa, unos derechos que los interesados tienen reconocidos por virtud de lo dispuesto por nuestro ordenamiento jurídico". Añade asimismo que "una vez adoptada la resolución resulta más comprometido rectificar y pretender que la Administración vuelva sobre sus propios pasos, máxime cuando se trata de un procedimiento administrativo que carece del carácter bilateral propio de otros procedimientos y en el que confluyen interesados de diverso signo que la Administración ha de valorar...La trascendencia del vicio de forma en que se incurre por la omisión del trámite de audiencia impide, pues, al acto alcanzar su fin, lo que es causa determinante de la anulabilidad de dicho acto, por virtud de lo dispuesto por el artículo 63.2 LRJAP-PAC".

Es en la STS de 6 de noviembre de $2015^{13}$ donde se cita la indefensión que se le causa al particular es el aspecto central de la misma ya que el hecho de no haber practicado determinada prueba hace que no se pueda calibrarse con total seguridad su resultado y por tanto su verdadera trascendencia para la resolución del caso. A este respecto se refiere a la STS de 23 de marzo de 2012 en la que se establece que "la posibilidad de cambio en el resultado del proceso, como consecuencia de la práctica de la prueba, es suficiente para incurrir en la indefensión proscrita en el artículo 88.2 de la LJCA, a los efectos de exigir su concurrencia para estimar el quebrantamiento de forma alegado...La prueba resulta decisiva en términos de defensa, porque, de hacerse practicado, la resolución final del proceso podría haber sido distinta o, al menos, hay dudas de que así hubiera podido suceder". Finalmente se acogió este motivo de casación y se procedió a ordenar la retroacción de actuaciones para la práctica de la prueba documental admitida". 
La STS 923/2016, de 27 de abril, se refiere a la indefensión causada por la falta de motivación en las resoluciones dictadas por la Administración. En concreto expone al igual que lo hace la STC 6/2002, "la obligación de motivar las Sentencias no es sólo una obligación impuesta a los órganos judiciales por el art. 120.3 CE, sino también, y principalmente, un derecho de los intervinientes en el proceso que forma parte del derecho fundamental a la tutela judicial efectiva proclamado por el art. 24.1 CE, que únicamente se satisface si la resolución judicial, de modo explícito o implícito, contiene los elementos de juicio suficientes para que el destinatario y, eventualmente, los órganos encargados de revisar sus decisiones puedan conocer cuáles han sido los criterios jurídicos que fundamentan la decisión. Es por lo tanto -y sobre todo- una garantía esencial para el justiciable mediante la cual es posible comprobar que la decisión judicial es consecuencia de la aplicación razonada del ordenamiento jurídico y no el fruto de la arbitrariedad. En conclusión, una Sentencia que no dé respuesta a las cuestiones planteadas en el proceso, o de cuyo contenido no puedan extraerse cuáles son las razones próximas o remotas que justifican aquélla, es una decisión judicial que no sólo viola la Ley, sino que vulnera el derecho a la tutela judicial efectiva"14.

En relación con esto, la jurisprudencia se refiere también a la motivación errónea estableciendo que "el derecho a obtener una resolución fundada en Derecho, favorable o adversa, es garantía frente a la arbitrariedad e irrazonabilidad de los poderes públicos. Ello implica, en primer lugar, que la resolución ha de estar motivada, es decir, contener los elementos o razones de juicio que permitan conocer cuáles han sido los criterios jurídicos fundamentadores de la decisión; y en segundo lugar, que la motivación debe contener una fundamentación en Derecho. Este último aspecto no incluye un pretendido derecho al acierto judicial en la selección, interpretación y aplicación de las disposiciones legales, pero sí conlleva la garantía de que el fundamento de la decisión sea la aplicación no arbitraria de las normas que se consideren adecuadas al caso, pues tanto si la aplicación de la legalidad es fruto de un error patente, como si fuere arbitraria, manifiestamente irrazonada o irrazonable no podría considerarse fundada en Derecho, dado que la aplicación de la legalidad sería tan sólo una mera apariencia"15.

Asimismo, respecto a la congruencia como integrante del derecho a la tutela judicial efectiva, la doctrina constitucional ha afirmado (por todas, STC 83/2009, de 25 de marzo), que: "...el derecho reconocido en el art. 24.1 CE comprende, junto a otros contenidos, el derecho a obtener una resolución congruente y razonable. Por lo que respecta a la primera de estas dos notas, la doctrina de este Tribunal acerca de la vulneración del derecho a la tutela judicial efectiva sin indefensión como conse-

$14 \quad$ RJ 2016\2232.

15 En esta misma línea, véase las SSTC 26/2009 de 26 de enero, 61/2009, de 9 de marzo y 82/2009 de 23 de marzo y $311 / 2005$, de 12 de diciembre. 
cuencia del dictado de una resolución judicial incongruente ha sido sistematizada en la STC 40/2006, de 13 de febrero en la cual afirmábamos lo siguiente:

Dentro de la incongruencia hemos venido distinguiendo, de un lado, la incongruencia omisiva o ex silentio, que se produce cuando el órgano judicial deja sin contestar alguna de las pretensiones sometidas a su consideración por las partes, siempre que no quepa interpretar razonablemente el silencio judicial como una desestimación tácita cuya motivación pueda inducirse del conjunto de los razonamientos contenidos en la resolución, y de otro lado, la denominada incongruencia por exceso o extra petitum, que se produce cuando el órgano judicial concede algo no pedido o se pronuncia sobre una pretensión que no fue oportunamente deducida por los litigantes, e implica un desajuste o inadecuación entre el fallo o la parte dispositiva de la resolución judicial y los términos en que las partes formularon sus pretensiones...Más concretamente, desde la perspectiva constitucional, este Tribunal ha venido declarando reiteradamente que, para que la incongruencia por exceso adquiera relevancia constitucional y pueda ser constitutiva de una lesión del derecho a la tutela judicial efectiva se requiere que la desviación o desajuste entre el fallo judicial y los términos en que las partes hayan formulado sus pretensiones, por conceder más de lo pedido (ultra petitum) o algo distinto de lo pedido (extra petitum), suponga una modificación sustancial del objeto procesal, con la consiguiente indefensión y sustracción a las partes del verdadero debate contradictorio, produciéndose un fallo extraño a las respectivas pretensiones de las partes, de forma que la decisión judicial se haya pronunciado sobre temas o materias no debatidas oportunamente en el proceso y respecto de las cuales, por consiguiente, las partes no tuvieron la oportunidad de ejercitar adecuadamente su derecho de defensa, formulando o exponiendo las alegaciones que tuvieran por conveniente en apoyo de sus respectivas posiciones procesales.

En algunas ocasiones, tiene declarado este Tribunal, ambos tipos de incongruencia pueden presentarse unidas, dándose la llamada incongruencia por error, que es aquélla en la que concurren al unísono las dos anteriores clases de incongruencia. En efecto, se trata de supuestos en los que, por error de cualquier género sufrido por el órgano judicial, no se resuelve sobre la pretensión o pretensiones formuladas por las partes en la demanda o sobre los motivos del recurso, sino que equivocadamente se razona sobre otra pretensión absolutamente ajena al debate procesal planteado, dejando al mismo tiempo aquélla sin respuesta" (por todas, SSTC 15/1999, de 22 de febrero; 124/2000, de 16 de mayo y 182/2000, de 10 de julio).

\section{El concepto de ciudadanía como buena administración en el ámbito comunitario.}

La Carta de Derechos Fundamentales de la Unión Europea, en concreto, en su artículo 41 hace referencia al concepto de ciudadanía y lo asocia con la buena 
administración. Es decir, la actuación de la Administración se considera correcta y adecuada siempre y cuando pivote sobre el concepto de ciudadano, haciendo de éste la razón de su existencia. En ese precepto se declara el derecho de toda persona a que las instituciones, órganos y organismos de la Unión traten sus asuntos imparcial y equitativamente dentro de un plazo razonable ${ }^{16}$.

Esta afirmación supone, en primer lugar, el derecho que tiene toda persona a ser oída antes de que se tome en contra suya una medida individual que le afecte desfavorablemente. En segundo lugar, supone también el derecho de toda persona a acceder al expediente que le afecte, dentro del respeto a los intereses legítimos de la confidencialidad y del secreto profesional y comercial. En tercer lugar, también se deduce la obligación que tiene la Administración de motivar todas y cada una de sus decisiones. En lo que respecta a la Unión, la buena administración también conlleva el derecho a la reparación por parte de la Unión de los daños causados por sus instituciones o agentes en el ejercicio de sus funciones de acuerdo a los principios generales comunes a los Derechos de los Estados miembros. Asimismo, la buena administración en la Unión Europea va ligada a que toda persona se pueda dirigir a las instituciones de la Unión en una de las lenguas de los Tratados así como recibir respuesta en esa misma lengua.

De todas estas afirmaciones, se concluye que existe un derecho-deber configurado desde la perspectiva del ciudadano como administrado, como titular de los derechos frente al poder que es la Administración. Sin embargo, el Convenio Europeo de Derechos Humanos no contempla entre su articulado el derecho a una buena administración, en el ámbito del Consejo de Europa se presta especial atención a los principios y reglas que deben aplicar las Administraciones públicas en sus relaciones con los particulares para el logro de una buena administración.

Efectivamente, la Carta fue el primer texto escrito en el que se recoge expresamente el derecho a una buena administración, pero, en el ámbito jurisprudencial

16 Véase BAENA DE ALCÁZAR, M., "Sobre la idea europea de buena administración”, Noticias de la Unión Europea, 247-248, 2005, pp. 61- 66; GUILLEM CARRAU, J., "La buena administración en la Unión Europea tras el Tratado de Lisboa: ¿Más por menos?", Corts: Anuario de Derecho Parlamentario, 25, 2011, pp. 69-103; MARTÍN-RETORTILLO BÁCQUER, L., "Dos notas sobre la Carta", en GARCÍA DE ENTERRÍA, E. y ALONSO GARCÍA, R., La encrucijada constitucional de la Unión Europea, ed. Civitas, Madrid, 2002, pp. 183-198; MELLADO RUIZ, L., "Principio de buena administración y aplicación indirecta del derecho comunitario: instrumentos de garantía frente a la "comunitarización" de los procedimientos", $R e^{-}$ vista Española de Derecho Europeo, 27, 2008, pp. 281-325; PONCE SOLÉ, J., El principio de buena administración: discrecionalidad y procedimiento administrativo, ed. Universitat de Barcelona, Barcelona, 2001 y TORNOS MAS, J., "El principio de buena administración o el intento de dotar de alma a la Administración pública", en Derechos fundamentales y otros estudios en homenaje al prof. D. Lorenzo Martín-Retortillo, Vol. I, ed. E1 Justicia de Aragón, Zaragoza, 2009. 
de la Unión Europea ya se hacía referencia previamente al principio de buena administración en la fundamentación de sus sentencias, no como derecho en sí mismo sino, más bien, como estándar de comportamiento exigido a la Administración en sus relaciones con los Estados miembros, sus organismos y agentes, o con los propios administrados.

La primera sentencia que hizo referencia al principio de la buena administración fue la Sentencia Industrias Siderúrgicas asociadas c. Alta Autoridad, al pronunciarse sobre la obligación de motivar las decisiones de la Alta Autoridad (Sentencia de 11 de febrero de 1955, asunto 4/54, ap. $6^{\circ}$ ). Asimismo, pueden destacarse las sentencias del Tribunal de Justicia dictadas en los casos Maurissen c. Tribunal de Cuentas, Burban e Interporc. La primera es la sentencia del Tribunal de Justicia de 4 de febrero de 1987, asunto 417/85. En ella señala que el principio de buena administración "implica, principalmente que, al resolver acerca de la situación de un funcionario, la autoridad debe tomar en consideración la totalidad de los elementos que puedan determinar su decisión, ya que, al hacerlo, tendrá en cuenta no sólo el interés del servicio, sino también el del funcionario interesado". La segunda es la Sentencia del Tribunal de Justicia de 31 de marzo de 1992, asunto C-255/90 P y la tercera es la Sentencia del Tribunal de Justicia de 6 de marzo de 2003, asunto C-41/00 P.

De las sentencias del Tribunal de Primera instancia destacan las dictadas en los casos Nölle (Sentencia de 18 de septiembre de 1995, asunto T-167/94) y New Europe Consulting (Sentencia de 9 de julio de 1999, asunto T-231/97). En la primera de ellas, el Tribunal hace referencia al deber de diligencia y de buena administración de las instituciones comunitarias y señala que el respeto de las garantías que otorga el ordenamiento jurídico comunitario en el procedimiento administrativo reviste una importancia aún superior cuando las Instituciones dispongan de amplias facultades de apreciación. Y en la segunda vuelve a referirse a la buena administración como un principio del que se deriva la obligación de actuar con toda la diligencia debida ${ }^{17}$.

17 Conviene hacer referencia igualmente al derecho a ser oído como expresión del derecho de defensa en el procedimiento administrativo en materia de competencia en la Sentencia Orkem (Sentencia del Tribunal de Justicia de 18 de octubre de 1989, asunto 374/87. Otras sentencias del Tribunal de Justicia son la de 12 de febrero de 1992, Países Bajos y Otros c. Comisión, asuntos acumulados C-48/90 y C-66/90, y la de 29 de junio de 1994, Fiskano c. Comisión, asunto C-135/92). Por otro lado, la sentencia Lisrestal (Sentencia del TPI de 6 de diciembre de 1994, Lisrestal, asunto T-450/93), en la que va a concluir constatando una vulneración del derecho de defensa de los demandantes, el Tribunal de Primera instancia añade a lo anterior que el principio de defensa «exige que cualquier persona contra la que pueda adoptarse una decisión lesiva tenga posibilidad de expresar efectivamente su punto de vista sobre los elementos que la Comisión formule en su contra para fundamentar la decisión controvertida». Destacan asimismo, las Sentencia del Tribunal de Justicia de 15 de octubre de 1987, Heylens, asunto 222/86 (ap. 15 y 16), o la de 21 de noviembre de 1991, TV Munchen, C-269/90. 
Pero a pesar de este reconocimiento en muchos pronunciamientos jurisprudenciales, hay que afirmar que no se llega a reconocer claramente un derecho subjetivo a una buena administración, en el sentido de la exigencia que tienen los ciudadanos para exigir a la Administración ciertas facultades o medidas en un momento concreto.

Por lo tanto, con el artículo 41 de la Carta se confiere unidad a una serie de derechos que se encontraban, bien dispersos en los Tratados, bien reconocidos a los particulares a través de su desarrollo jurisprudencial.

Por ello, aunque los derechos que se engloban en la buena administración ya venían siendo invocados desde diversas instancias y reconocidos por el Tribunal de Justicia, es con la entrada en vigor del Tratado de Lisboa, y la consiguiente adquisición de valor jurídicamente vinculante, cuando el pleno respeto a los mismos se convierte en una obligación jurídica para la Administración Europea. En consecuencia, los particulares encuentran reconocidos en el artículo 41 de la Carta una serie de derechos de carácter procedimental, que deben ser respetados en los distintos ámbitos de aplicación del Derecho europeo.

$\mathrm{Ni}$ el derecho a una buena administración como principio informador, ni los específicos derechos subjetivos que lo forman no tienen una mayor protección por el hecho de que la Carta adquirió fuerza jurídica con el Tratado de Lisboa, ya que con anterioridad a la entrada en vigor del mismo, la tutela de tales derechos la llevaba a cabo el Tribunal de Justicia de acuerdo a los preceptos de los Tratados o basándose en el artículo 41 de la Carta.

\section{El principio de buena administración en el ámbito español.}

Vista la regulación por parte del Derecho comunitario del principio de buena administración, conviene hacer referencia a la incorporación en nuestro ordenamiento jurídico del mismo.

El culto a la justicia no consiste sólo en el culto a la legalidad, pues ella nos impone siempre una participación activa e infatigable en el eterno drama, que tiene por teatro la historia y por argumento la lucha entre el bien y el mal, el derecho y la

En este última, el Tribunal se refiere a dos manifestaciones del derecho a una buena administración que deben ser respetadas en el marco del procedimiento administrativo desarrollado ante una institución comunitaria (en este caso la Comisión), a saber, el derecho a ser oído que exige que la parte interesada esté en situación «de definir su postura y manifestar eficazmente su punto de vista sobre la importancia de los hechos así como, en su caso, sobre los documentos en los que se basa la Institución comunitaria», y la motivación, en cuya virtud, debe constar de modo claro e inequívoco el razonamiento de la autoridad comunitaria de quien procede el acto impugnado, a fin de permitir a los interesados conocer las justificaciones de la medida adoptada para que puedan defender sus derechos, e igualmente permitir al Tribunal ejercer su control. 
infracción; las leyes no sólo deben ser obedecidas, sino vivificadas, cooperando a su renovación.

Como punto de partida, hay que comenzar por los artículos 9.3 y 103 de la Constitución, reconociendo el primero "el principio de legalidad, la jerarquía normativa, la publicidad de las normas, la irretroactividad de las disposiciones sancionadoras no favorables o restrictivas de derechos individuales, la seguridad jurídica, la responsabilidad y la interdicción de la arbitrariedad de los poderes públicos" y el segundo que "la Administración Pública sirve con objetividad los intereses generales y actúa de acuerdo con los principios de eficacia, jerarquía, descentralización, desconcentración y coordinación, con sometimiento pleno a la ley y al Derecho. Los órganos de la Administración del Estado son creados, regidos y coordinados de acuerdo con la ley. La ley regulará el estatuto de los funcionarios públicos, el acceso a la función pública de acuerdo con los principios de mérito y capacidad, las peculiaridades del ejercicio de su derecho a sindicación, el sistema de incompatibilidades y las garantías para la imparcialidad en el ejercicio de sus funciones".

El segundo paso lo marca la LRJPAC en su artículo 3 reconociendo igualmente los principios de eficacia, jerarquía, descentralización, desconcentración y coordinación, con sometimiento pleno a la Constitución, a la Ley y al Derecho; los principios de buena fe y de confianza legítima; el principio de cooperación y colaboración, el principio de eficiencia y servicio a los ciudadanos y los principios de transparencia y de participación.

El siguiente escalón es la Ley 6/1997, de Organización y Funcionamiento de la Administración General del Estado (LOFAGE) ya que en ella también se incluyen y reconocen los principios de economía, suficiencia, simplicidad, claridad y proximidad a la ciudadanía, eficiencia en la asignación y utilización de los recursos públicos, programación y desarrollo de los objetivos, control de la gestión y de los resultados y responsabilidad por la gestión pública, racionalización y agilidad de los procedimientos administrativos.

Además de esta normativa general, hay que hacer referencia a que también en el ámbito autonómico se ha ido incorporando el reconocimiento de los derechos de los ciudadanos a una buena administración. Como reflejo de ello, y sin entrar de forma detallada en cada uno de los Estatutos de Autonomía, las modificaciones de los Estatutos de Autonomía han venido a reforzar estos derechos ${ }^{18}$. Así por ejemplo, es

18 GALVO SÁNCHEZ, M M. D., "Objetivos de la reforma. Ámbito de aplicación. Principios rectores. Derechos de las personas y derechos de los interesados", en el vol. col. GALLARDO CASTILLO, M ${ }^{\mathrm{a}} \mathrm{J}$. (Dir.), Aproximación al nuevo procedimiento administrativo común de la Ley 39/2015: reflexiones y claves para su aplicación, ed. Centro de Estudios Municipales y de Cooperación Interprovincial, Madrid, 2016, pp. 19-77; RODRÍGUEZ ARANA MUÑOZ, J., El buen gobierno y la buena administración de las instituciones públicas, ed. Thomson 
el caso de la Comunidad Valenciana que en la modificación de su Estatuto mediante Ley Orgánica 1/2006, de 10 de abril, establece expresamente que una ley debe regular una buena administración y el acceso a los documentos de las instituciones y administraciones públicas valencianas.

De la misma manera, establece que los ciudadanos tienen derecho a que la administración trate sus asuntos de modo equitativo e imparcial y en un plazo razonable. Lo mismo ocurre con otras Comunidades Autónomas como Andalucía, en la que en la modificación de su Estatuto llevada a cabo por la Ley Orgánica 2/2007, de 19 de marzo, también se incluye un precepto con el título de buena administración. O el caso de Castilla y León, que de modo más amplio, mediante la Ley Orgánica 14/2007, de 30 de noviembre, garantiza que los ciudadanos tienen derecho a recibir información suficiente sobre los servicios y prestaciones a los que pueden acceder, a un tratamiento imparcial y objetivo de los asuntos, a acceder a los archivos y registros administrativos, a formular quejas sobre el funcionamiento de los servicios públicos, etc.

La efectividad y preservación de estos derechos debe estar ligada a que su incumplimiento o incluso su negación, lleve consigo la nulidad del acto dictado por la Administración, en base a lo dispuesto en el artículo 62.1 de la LRJPAC (actual artículo 47 de la nueva Ley de Procedimiento). Es por ello que existe jurisprudencia variopinta en la que, por un lado, hay sentencias que de forma tajante afirman la nulidad de actuaciones en base a una infracción en el procedimiento por incumplimiento de los derechos que tiene el ciudadano pero hay otras sentencias que lo califican como mero error formal de lo que se deduce que el derecho del ciudadano queda claramente relegado a un segundo plano.

Dentro del concepto de buena administración, hay que incluir la obligación que tiene la Administración de motivar todas y cada una de sus decisiones, en el sentido de que el ciudadano debe conocer cuáles han sido las justificaciones o motivos que ha utilizado para dictar la resolución en cuestión (art. 35 de la nueva Ley de Procedimiento). De lo contrario, como es sabido, incurre en arbitrariedad, práctica absolutamente prohibida. En este sentido, la jurisprudencia en relación con esta exigencia de la motivación, exige que la misma sea clara y expresa. De esto se deduce que la Administración debe dar sus razones jurídicas y no jurídicas que le han llevado a dictar la resolución, con el objetivo último de que el ciudadano las conozca por si se plantea impugnarla y de que los Tribunales también puedan valorar los motivos planteados por la Administración.

Aranzadi, Cizur Menor, 2006 y URIARTE RICOTE, M., "El derecho a una buena administración como garantía de un ejercicio de poder democrático", Carta de los Derechos Fundamentales de la Unión Europea y su reflejo en el ordenamiento jurídico español, ed. Thomson-Reuters Aranzadi, Cizur Menor, 2014, pp. 715-732. 


\section{LA EVOLUGIÓN DEL DEREGHO ADMINISTRATIVO: DEL DERECHO DEL PODER AL DERECHO DE LA PERSONA A UNA BUENA ADMINISTRACIÓN.}

\section{El incremento del protagonismo de la sociedad.}

El Estado de Derecho no se denomina así por la sujeción del poder al derecho sino que su sentido es el del reconocimiento y la garantía de los derechos e intereses de los particulares. También encuentra su sentido en la intervención de los poderes públicos en la acción positiva de la Administración (art. 9.2. CE).

Es decir, el poder o lo que es lo mismo, la Administración, debe estar al servicio de los derechos y obligaciones del ciudadano. La Administración, como poder público o ente público, posee una serie de poderes que un sujeto particular carece por completo de ellos. La potestad es una manifestación de la personalidad consistente en un poder efectivo, atribuido directamente por el ordenamiento, previo e independiente de toda relación jurídica concreta y susceptible de actuar frente a personas que se encuentran en situación de sujeción.

El Estado ya no es un vínculo entre individuos utilizado para los fines e intereses de los individuos. Es cierto que posee una serie de prerrogativas como poder público que es, pero por el contrario deben existir derechos y garantías de los ciudadanos para equilibrar esa supremacía que tiene la Administración.

La Administración es un ente común, una institución que está por encima de los individuos y que persigue intereses que no son la suma de los intereses de algunos individuos, sino que son intereses colectivos y generales. El centro de gravedad se encuentra en el interés público y éste debe estar al servicio de los ciudadanos, no a la inversa. La posición de que el ciudadano es el sujeto que asume, obedece y padece las actuaciones de la Administración debe quedar atrás. Esta premisa es fundamental para entender cómo debe articularse el Derecho Administrativo y hacia dónde debe tender en todo caso.

El administrado y la sociedad en su conjunto ha dejado de ser un mero objeto pasivo, receptor de las actuaciones del Estado para ir adquiriendo poderes en sectores importantes de la sociedad en la que vivimos. Esto también se ha producido por el traslado del centro de poder de la Administración a los particulares en todo lo relacionado con los servicios públicos impropios. En la concepción clásica, la Administración era la encargada de suministrar y ofrecer los servicios que se consideraban esenciales para la ciudadanía y podía encomendar o no la gestión de los mismos a empresas y particulares. Sin embargo, esto fue evolucionando a que las empresas pueden igualmente ofrecer tales servicios básicos y en las mismas condiciones que lo haría la Administración. Por lo que es un claro ejemplo de este cambio de poder. 
GARCÍA PELAYO ya se refirió a esta realidad exponiendo que el Estado se ve incapaz de absorber la creciente complejidad de su ambiente y de reaccionar a las transformaciones sociales que van aconteciendo ${ }^{19}$.

Otro ejemplo que apunta en esta dirección es que en el régimen de las autorizaciones, el centro de poder también reside en la Administración ya que ésta de forma previa a la realización de la actividad exige del particular que la va a llevar a cabo que éste solicite dicha autorización con la que podrá llevar a cabo la actividad en las condiciones que la Administración le fije. Por lo que la acción de la Administración supone un requisito previo sin el cual el particular no puede realizar la actividad. Sin embargo, con el nuevo régimen de declaración responsable y comunicación previa, el centro de poder ya no reside en la Administración, se ha trasladado al particular ya que éste es el que presenta los documentos donde indica el tipo de actividad a realizar y el cumplimiento de los requisitos exigidos. Por ello, la Administración queda relegada a un plano de supervisión y control posterior a la actividad realizada, ya no se sitúa en el momento previo ni su actuación es un requisito previo.

Se trata de dos ejemplos donde se manifiesta el cambio producido respecto de la posición del Estado y parece que lo aconsejable es de hablar de un Estado cooperativo, de buscar los medios para que el Estado colabore con los agentes sociales. ESTEVE PARDO en este sentido recalca la necesidad de establecer y fijar el concepto de bien común o interés general. Efectivamente, es el concepto clave del Derecho Administrativo ya que la Administración tiene que perseguirlo en todas y cada una de sus actuaciones. Y es un bien común que está por encima de los intereses particulares, lo trasciende. A este respecto, PAREJO ALFONSO expone que "la reticencia al recurso a medios imperativos y de intervención, unida a la mayor dependencia de la colaboración de los particulares, dificulta la influencia en los comportamientos de los actores sociales" ${ }^{\prime 20}$.

\section{La nueva realidad del Estado garante.}

El Estado por ello debe garantizar ese bien común en todas las situaciones ya que los particulares a pesar de ir asumiendo titularidades y esferas de poder, no tiene la capacidad para" articular, definir y garantizar el bien común" ${ }^{21}$. Es el denominado Estado garante, un Estado que abandona su posición de dominio pero que debe

19 GARCÍA PELAYO, M., Las transformaciones del Estado contemporáneo, ed. Alianza, Madrid, 1977 y PAREJO ALFONSO, L., "Estado y proceso de cambio. Del Estado prestacional al garante de la prestación", Asamblea: Revista Parlamentaria de la Asamblea de Madrid, 33, 2015, pp. 73-98.

20 PAREJO ALFONSO, L., "Estado y proceso de cambio. Del Estado prestacional al garante de la prestación", cit., p. 82.

21 ESTEVE PARDO, J., La nueva valoración entre Estado y sociedad, ed. Marcial Pons, Madrid, 2013, p. 175 . 
garantizar el interés general aún cuando la titularidad de los medios está en manos de sujetos privados.

El papel que entonces debe asumir el Estado es garantizar que las actuaciones en manos del sector privado atiendan al interés general, es decir, como si dichas actuaciones las llevara a cabo la Administración. De ahí la denominación de Estado garante, no realiza las actuaciones pero sí garantiza que con ellas se beneficia al máximo número de población. El Estado ha dejado de tener una presencia activa en todos los sectores cediendo el paso a la iniciativa privada. Tiene la misión de "mantener los fines sin disponer de los medios"22, por lo que tiene una responsabilidad de garantía de esas prestaciones sirviendo de instrumento para que las actividades desarrolladas por el sector privado se materialicen persiguiendo en todo caso el interés general.

En este contexto, para referirse a esa realidad surgen conceptos como el de "responsabilidad compartida" 23 , el de "gobernanza público-privada"24 o el de "gobernanza cooperativa" 25 .

El problema, al que se refiere ESTEVE PARDO, es que por esas realidades descritas surge la conveniencia de establecer mecanismos de protección respecto del Estado y de los intereses generales, ya que al estar muchos sectores en manos de particulares, puede haber el riesgo de que los intereses privados pueden prevalecer frente a los intereses generales. De ahí, el autor se refiere a la aplicación a dichos sujetos de las reglas de Derecho público.

Cabe hacer referencia a la STS de 1 de octubre de 2008 en la que se dispone que "la actuación de la Comisión del Mercado de las Telecomunicaciones en la resolución del conflicto de interconexión entre los operadores contendientes Amena y Vodafone no requiere de la apelación a las doctrinas civilistas sobre el riesgo imprevisible, la ruptura del equilibrio contractual de la base del negocio o la frustración o novación del contrato por causas que hagan imposible o gravoso su cumplimiento por una de las partes, porque la función del órgano regulador se atiene a lograr el «equilibrio justo entre los intereses de las partes», con el objeto de garantizar los in-

22 ESTEVE PARDO, J., "La Administración garante. Una aproximación”, Revista de Administración Pública, 197, 2015, p. 21. Asimismo, véase CARRO FERNÁNDEZ-VALMAYOR, J. L., "Reflexiones sobre las transformaciones actuales del Derecho Público, en especial del Derecho Administrativo", Revista de Administración Pública, 193, 2014, pp. 11-44.

23 SCHMIDT-ASSMANN, E., "La ciencia del Derecho administrativo ante el reto de la internacionalización de las relaciones administrativas", Revista de Administración Pública, 171, 2006, pp. 7-34.

24 NOVAK, N. J., "Public-private gobernance: a historical introduction", en FREEMAN, J. \& MINOW, M. (eds.), Government by contract, ed. Harvard University Press, Cambridge, 2009.

25 FREEMAN, J., "Collaborative gobernance in the administrative state", UCLA Law Review, 45, 1997, pp. 1-99. 
tereses públicos vinculados a la salvaguarda de la libre competencia entre empresas y el interés de los usuarios"26 (F. J. $7^{\circ}$ ).

En este punto, hay sectores que apuntan hacia la autorregulación normativa fundamentalmente en el ámbito internacional en el sentido de que son las empresas y los profesionales de un determinado sector quienes mejor conocen los aspectos que deben regularse destacando los riesgos que existen a diferencia de lo que le ocurre al legislador, el cual se encuentra en muchos ámbitos concretos con dificultades para conocer todas las especificidades técnicas existente ${ }^{27}$. Sin embargo, estos estándares privados internacionales encargados de esa regulación deben ser controlados y deben existir garantías en cuanto al procedimiento, la organización y la forma de actuación administrativa.

Por lo tanto, es evidente que nos encontramos ante una administración desbordada y ante una sociedad fortalecida. Y esta realidad obliga a un replanteamiento de las relaciones que se van a crear entre Administración y sociedad ya que los tiempos han cambiado, la sociedad también y el derecho sigue a la realidad y sirve a las personas, tal como dice la frase citada al inicio de este artículo. "El Derecho es una idea cultural y una idea práctica... es un material que depende del contexto en el que vive. No hay un derecho aséptico, objetivo, neutro" ${ }^{28}$. Constituye un sistema, tal como lo expone la STS de 21 de febrero de 1979, "un sistema unitario y orgánico de reglas, interrelacionadas, que está sometido a un constante proceso de transformación determinado por la aparición continua e incesante de nuevas realidades sociales y culturales de todo orden y esta cualidad dinámica y global del mundo de la juridicidad... no constituye mera construcción teórica en cuanto tiene apoyo positivo en nuestro Derecho".

ESTEVE PARDO señala dos caminos para la extensión del Derecho público que son, por un lado, el camino objetivo que supone la aplicación del Derecho Público a ciertas relaciones entre particulares cuando ejercitan funciones públicas o un camino subjetivo que supone la concesión de cierto estatus público a sujetos privados que ejercen funciones públicas ${ }^{29}$.

\footnotetext{
$26 \quad$ RJ 2008\4601.

27 ESTEVE PARDO, J., Autorregulación. Génesis y efectos, ed. Aranzadi, Cizur Menor, 2002 y DARNACULLETA I GARDELLA, M., "Autorregulación normativa y derecho a la globalización”, en el vol. col. DARNACULLETA I GARDELLA, M., ESTEVE PARDO, J. y SPIECKER GEN. GÖHMANN, I. (Eds.), Estrategias del Derecho ante la incertidumbre y la globalización, ed. Marcial Pons, Madrid, 2015, pp. 197-216. Igualmente, LAGUNA DE PAZ, J. C., "Regulación, externalización de actividades administrativas y autorregulación”, Revista de Administración Pública, 185, 2011, pp. 89-112.

28 MARTÍN REBOLLO, L., "El procedimiento como garantía (una reflexión sobre el fortalecimiento de las formas y la reducción de los principios)", en el vol. col. LÓPEZ MENUDO, F. (Dir.), Derechos y garantías del ciudadano, ed. Iustel, Madrid, 2011, p. 788 y MARTÍN REBOLLO, L., "La Administración de garantías: vigencia y limitaciones", cit.

29 ESTEVE PARDO, J., "La Administración garante. Una aproximación”, cit., p. 35. Igualmente, se refiere a esta función garantista en Lecciones de Derecho administrativo, ed. Marcial Pons, Madrid, 2015, p. 175.
} 
Si la realización de las actuaciones recae en la iniciativa privada y la Administración debe garantizar que se lleve a cabo de forma correcta, lo que se produce es un aumento o refuerzo de las funciones de dirección, supervisión y control por parte de la Administración. En la privatización de ciertos sectores los sujetos privados llevan a cabo funciones públicas, y "en la medida en que en la privatización funcional cabe hablar, así, de un condominio estatal-sujetos privados sobre las tareas y los cometidos correspondientes, es posible jurídicamente, finalmente, la privatización funcional también de la propia supervisión (dando así lugar a la retención por la Administración de una supervisión superior o última)"30.

WAECHTER expone que se debe crear un marco único para todos los tipos de actuaciones por parte de la Administración que son la intervención, prestación y configuración social. Las ventajas que explica de este modelo, en primer lugar, son la identificación de la situación de concurrencia y complementariedad de la Administración y la sociedad en la satisfacción de las necesidades sociales. En segundo lugar, la integración de todas las formas de actuación de la Administración y asimilación de los procesos de privatización de actividades que anteriormente eran públicas. En tercer lugar, delimitación de la responsabilidad que adquieren los agentes sociales y relaciones de éstos con la Administración y en último lugar, enumeración de los principios que rijan a la Administración que inspiren su actuación ${ }^{31}$.

Por concluir el apartado, también hay voces que apuntan hacia un Estado activador, con origen en Alemania, cuya pretensión es que el Estado posea funciones de dirección y configuración dando protagonismo al tercer sector. El objetivo, por tanto, es que la responsabilidad se comparta entre Estado, economía, tercer sector y ciudadanos.

\section{EN BÚSQUEDA DEL EQUILIBRIO: LAS NEGESARIAS GARANTÍAS DEL ADMINISTRADO RESPECTO DE LA ADMINISTRACIÓN.}

\section{Conceptos de deber, derecho subjetivo y sujeción.}

El concepto de deber supone que, al igual que la obligación, implica un "comportamiento positivo o negativo que se impone a un sujeto en consideración a intereses que no son los suyos propios, sino los de otro sujeto distinto o los generales de la colectividad". El deber en sentido estricto tiene su origen directamente en la norma y no en una relación o negocio jurídico concreto; por tanto, frente al gravado por un

\footnotetext{
30 PAREJO ALFONSO, L., "Estado y proceso de cambio. Del Estado prestacional al garante de la prestación", cit., p. 97.

31 PAREJO ALFONSO, L., "Estado y proceso de cambio. Del Estado prestacional al garante de la prestación", cit., p. 86.
} 
deber no existe un sujeto titular de un derecho subjetivo. Un ejemplo puede ser el deber de prestar el servicio de agua potable y saneamiento anteponiendo razones de orden social a las de orden económico.

Por derecho subjetivo se entiende que es la "prerrogativa concedida a una persona por el Derecho objetivo y garantizada con vías de derecho, de disponer como dueño de un bien que se reconoce que le pertenece, bien como suyo, bien como debido" "32. WINDSCHEID expresa que el derecho subjetivo es un deber o señorío concedido a la voluntad por el ordenamiento jurídico positivo. Para IHERING, siguiendo la teoría del interés, la voluntad es la fuerza motriz del derecho subjetivo, pero éste existe en razón de intereses o fines que el individuo desea alcanzar. A partir de esta observación, IHERING expresa que el derecho subjetivo es un interés jurídicamente protegido. El derecho subjetivo se entiende como:

a) como derecho de libertad jurídica (que permite al titular optar entre ejecutar o no una conducta),

b) como poder de creación de derechos y deberes, o poder jurídico (que permite al titular crear nuevos derechos y obligaciones, por ejemplo, el poder para constituir una fundación),

c) como pretensión o derecho a exigir el cumplimiento del deber ajeno (por ejemplo, en el caso del acreedor respecto del deudor),

d) como derecho de cumplir el propio deber (por ejemplo, el derecho del deudor de pagar por consignación cuando el acreedor se rehúsa a cobrarle).

El derecho subjetivo es un poder a favor de un sujeto concreto que puede hacer valer frente a otros sujetos, imponiéndoles obligaciones o deberes, en su interés propio, reconocimiento que implica la tutela judicial de dicha posición.

Analizando esta definición, el derecho a pedir algo sobre otro sujeto, puede ser de un sujeto respecto de la Administración o también de la Administración respecto de un sujeto, ya que la Administración puede exigir que un determinado sujeto le conceda algo en virtud de la relación jurídica existente entre ambos. Este es el caso, por ejemplo, de la relación que se crea por la concesión de una determinada ayuda económica. La Administración concede al sujeto una beca, por ejemplo, con la condición de que dicho sujeto la destine a determinado objetivo con la consiguiente

32 DABIN, J. (ed. MONEREO PE'REZ, J. L.), El derecho subjetivo, ed. Marcial Pons, Madrid, 2006, p. 130 . 
obligación de que el sujeto beneficiario le certifique que ha realizado eso que ha justificado la concesión de la beca en cuestión.

Por último, el concepto de sujeción es la eventualidad de soportar consecuencias, normalmente desventajosas, aunque pueden también no serlo, del ejercicio de una potestad.

\section{Concepto de garantía como salvaguarda frente a la Administración.}

Se entiende por "garantía" la acción de asegurar, proteger, defender o salvaguardar el cumplimiento de una obligación. Por ello, aplicado este concepto al Derecho Público, supone diversas protecciones a favor del ciudadano o dicho de otro modo, seguridades institucionales para posibilitar la vigencia de los derechos reconocidos al ciudadano. Parece que realmente cuando se puede hablar de protección integral respecto del ciudadano es al referirnos a la garantía jurisdiccional porque parece que es cuando el derecho puede ser alegado y defendido de manera efectiva por su titular ante el Poder jurisdiccional.

Parece que la defensa de la persona es más una defensa del cliente, de un Derecho Administrativo del cliente ya que los abogados defienden en los pleitos al cliente en particular, a los intereses afectados, nada más.

Las garantías jurídicas tienen por objeto la defensa de los derechos e intereses legítimos de los particulares y son puestas en movimiento a instancia de los interesados, pudiendo exigirse incluso responsabilidades no sólo a los administradores, sino de carácter civil a la Administración, aunque en definitiva salga también ésta gananciosa con la restauración de orden jurídico perturbado. Comprenden dos aspectos: primero, la exigencia de que se proporcione a la Administración un régimen para su actuación, señalando los requisitos de forma, trámites y procedimientos de los actos administrativos: segundo, el establecimiento de los modos de fiscalizar los actos administrativos. Pero la tutela en este segundo aspecto puede serlo en garantías que se basan en la jerarquía administrativa, como el procedimiento administrativo, en la relación de una fiscalización de los actos administrativos por órganos extraños a la Administración, como es el procedimiento jurisdiccional ${ }^{33}$.

En esta misma línea, los derechos fundamentales no suponen sólo una barrera frente a la actuación de los poderes públicos sino que también constituyen elementos

33 HUERGO LORA, A. J., "Las leyes 39 y 40/2015. Su ámbito de aplicación y la regulación de los actos administrativos", El Cronista del Estado Social y Democrático de Derecho, 63, 2016, pp. 4-13. 
primordiales del ordenamiento jurídico ${ }^{34}$. Por lo que la Administración y en general los poderes públicos deben velar para que todos los ciudadanos disfruten de los mismos. De hecho, este es el contenido del artículo 9.2 de la Constitución que establece que "corresponde a los poderes públicos promover las condiciones para que la libertad y la igualdad del individuo y de los grupos en que se integra sean reales y efectivas; remover los obstáculos que impidan o dificulten su plenitud y facilitar la participación de todos los ciudadanos en la vida política, económica, cultural y social”.

El reconocimiento de los mismos supone un presupuesto del Estado social y la intervención del Estado en la esfera del particular justamente encuentra su fundamento último en la existencia de tales derechos fundamentales y de su protección, debiendo la Administración intervenir con la menor intensidad posible. Los derechos fundamentales suponen deberes estatales de garantía prestacional. Es decir, por poner un ejemplo, la intervención policial está fundamentada en la preservación de la seguridad y del orden público de los ciudadanos ${ }^{35}$.

Parece que la función del Estado es que sólo debe hacer aquello que los ciudadanos no pueden realizar por sí mismos, o que no pueden hacer con resultados tan positivos como el Estado.

\section{El derecho de defensa como garantía del particular ante la Administración.}

En esencia, el derecho de defensa engloba en sí mismo otros derechos como son el derecho a la personación, el derecho a formular alegaciones y el derecho de audiencia con anterioridad a que la Administración dicte su resolución en un determinado procedimiento (arts. 23, 26, 83 y 91 de la LRJPAC).

Teóricamente con estos tres derechos, el particular que se ha visto afectado por una actuación de la Administración, tiene la posibilidad de conocer cuáles han sido las actuaciones concretas que el órgano administrativo ha llevado a cabo. Sin embargo, en la realidad no es del todo así, ya que parece que simplemente con esos derechos el particular puede manifestar su visión de los hechos, plantear su punto de vista respecto de la actuación administrativa pero el conocimiento global y pleno de lo realizado por la Administración no se consigue. En palabras de ESCRIBANO, "el procedimiento administrativo no es transparente para los interesados, difícilmente

34 RIVERO ORTEGA, R., El Estado vigilante. Consideraciones jurídicas sobre la función inspectora de la Administración, ed. Tecnos, Madrid, 2000, p. 117.

35 LÓPEZ MENUDO, F. (Coord.), Derechos y garantías del ciudadano: estudios en homenaje al profesor Alfonso Pérez Moreno, ed. Iustel, 2011 y SÁNCHEZ SOCÍAS, L., "Garantías del ciudadano frente a la Administración pública: panorama general”, en el vol. col. Gobierno y Administración en la Constitución, ed. Dirección General del Servicio Jurídico del Estado, vol. 2, 1988, pp. 1727-1786. 
se conocen y mucho menos se llegan a entender los intereses que defiende la Administración que no se comporta como una parte más explicitando sus pretensiones y argumentos, sino como casi un juez o tribunal, ajeno a las actuaciones practicadas y que fallará no se sabe bien en qué términos"36. Por esta razón, surge en la persona una desconfianza ante las actuaciones administrativas que conlleva a éste a dirigirse a los tribunales de justicia para que sean éstos quienes resuelvan las dudas sobre la legalidad o no por parte de la Administración.

Por ello, considero indispensable enfatizar el carácter garantizador del procedimiento administrativo permitiendo asimismo una plena participación real en tal procedimiento. Y por ello, la Administración no debe entenderse como un Tribunal, sino como una parte del procedimiento frente a la que los ciudadanos afectados puedan ejercitar su derecho de defensa.

En relación con la posibilidad que tiene el interesado de impugnar la actuación por parte de la Administración, como decía anteriormente, resulta triste que la vía administrativa no sea lo eficaz que debiera. Como dice PRATS, "lo que interesa al ciudadano es que los recursos administrativos se resuelvan bien, es decir, con celeridad, objetividad y acierto técnico...Lo que interesa realmente a los ciudadanos es que el servicio y sistema de recursos administrativos funcione correctamente" 37 .

De lo que se trata es que los recursos administrativos sean una garantía real para la persona. Y tal como siempre han estado configurados, y como están en la actualidad, son recursos fundamentados en la jerarquía entre los órganos administrativos intervinientes. Si el órgano autor del acto impugnado tiene un superior jerárquico, éste es el que va a resolver el recurso de alzada interpuesto contra a aquél. En este caso, por lo menos, es otro órgano diferente al autor del acto el que valora la legalidad o no del mismo. Pero en el caso del recurso de reposición, en el que el órgano autor del acto no tiene superior jerárquico, de lo que se trata en esencia es que el mismo órgano revise de nuevo la actuación que él mismo ha decretado. Por lo tanto, desde el prisma de la persona, no es más que un retraso en el tiempo para acceder con posterioridad a la justicia.

En este sentido, se puede citar la STC 60/1989 que establece que la vía administrativa previa tiene sentido por la "conveniencia institucional de dar a la Administración la oportunidad de conocer las pretensiones de sus trabajadores antes de que acudan a la jurisdicción, y evitar así el planteamiento de litigios o conflictos ante los

36 ESCRIBANO COLLADO, P., "Reflexiones sobre la indefensión en el procedimiento administrativo", cit., p. 547.

37 PRATS CATALÁ, "La reforma del procediment administratiu i del régime de recursos administratius", en el vol. col. Potestat normativa, participatió, bens u contractació, ed. Ajuntament de Barcelona, Barcelona, 1989. 
tribunales". La vía de recurso administrativa es un medio de defensa complementario al judicial, no es un filtro de la vía judicial. Ya hace varios años, T. R. FERNÁNDEZ, al referirse a estos aspectos, señaló que "la diferenciación por sectores es absolutamente esencial para formar un juicio correcto acerca de la utilidad y eficacia reales de la institución, que difícilmente puede ser valorada con acierto desde una perspectiva general" 38 .

Parece que en la realidad la vía contencioso-administrativa es vista por las personas como la única garantía real de defensa de sus derechos por lo que ha supuesto un aumento muy considerable del número de recursos que se han planteado con todos los problemas de retraso que se plantean. En la propia exposición de motivos de la Ley de la Jurisdicción, se establece que el control de la legalidad de las actividades administrativas puede y debe ejercerse asimismo por otras vías complementarias de la judicial, que sería necesario perfeccionar para evitar la proliferación de recursos innecesarios y para ofrecer fórmulas poco costosas y rápidas de resolución de numerosos conflictos.

Ante esta realidad, se han aprobado diversas leyes con la finalidad de reducir la carga de trabajo de los órganos jurisdiccionales contencioso-administrativos. Tal es el caso de la Ley 37/2011, de 10 de octubre que elevó la cuantía de los asuntos en los que las sentencias y autos son susceptibles de apelación y casación y estableció el criterio de la condena en costas por vencimiento incluso en la primera instancia. Asimismo, la Ley 10/2012, de 20 de noviembre, exige el pago de una tasa judicial para interponer los recursos contencioso-administrativos y ha suprimido la facultad de los funcionarios de comparecer y defender por sí mismos sus derechos estatutarios ante la jurisdicción con la consecuente obligación de contar con un abogado y si se trata de órganos colegiados con un procurador.

Estas modificaciones legislativas suponen una merma de las garantías que tiene el particular ante la Administración, ya que un gran sector de la población, y más en tiempos de crisis económica como la que nos encontramos, no puedan ejercer su derecho a la tutela judicial efectiva por carecer de medios económicas y, por lo tanto, se les perjudica su garantía de defensa ante la Administración. En consecuencia, el administrado ve que sus posibilidades de impugnar la actuación de la Administración en vía administrativa no son eficaces por las escasas posibilidades de éxito de sus pretensiones y puede ocurrir que no se pueda plantear dicha impugnación en vía judicial por no ser demasiado solvente desde el punto de vista económico. Por lo tanto, el panorama es desolador.

38 FERNÁNDEZ RODRÍGUEZ, T. R., "Reflexiones sobre la utilidad de la vía administrativa de recurso", Documentación Administrativa, 221, 1990, pp. 5-12. 
Otra medida que beneficiaría a este sistema de recursos administrativos es que los órganos encargados de resolver no sean ni el superior jerárquico en el caso del recurso de alzada ni el mismo órgano en el caso del recurso potestativo de reposición, sino que fueran órganos separados de esa línea jerárquica, especializados en esas materias, quienes resolvieran los recursos que las personas planteen en vía administrativa. En esa misma línea, otra cuestión también por lo menos cuestionable es el hecho de que para poder impugnar una resolución en la vía judicial sea necesario agotar previamente la vía administrativa, es decir, recurrir dicha resolución ante la Administración. Se convierte en un privilegio para la Administración y en una carga para el ciudadano, afectando claramente al principio de igualdad.

En la línea de proponer soluciones o medios alternativos, se han previsto ya por parte de algunos ámbitos sectoriales otras garantías que sustituyan al sistema clásico de recursos administrativos. Se trata de pensar en "otro tipo de recursos o reclamaciones no judiciales de amplia y fácil accesibilidad, agilidad en la tramitación e independencia en la resolución" ${ }^{39}$. Un ejemplo puede ser el de la mediación que no ha acabado de implantarse del todo en el Derecho Administrativo, en recurso administrativo especial en materia de contratación pública, el recurso especial ante el Tribunal Administrativo del Deporte, la reclamación ante el Consejo de Transparencia y Buen Gobierno, la reclamación ante la Secretaría del Consejo para la Unidad del Mercado $^{40}$. Se trata de casos cuya resolución se encomienda a órganos creados ad hoc y que en la mayoría de los casos están dotados de independencia funcional.

Como decía anteriormente, el derecho de defensa engloba, en primer lugar, el derecho de personación que es el derecho de los interesados de acceder al procedimiento administrativo bien por su propia iniciativa o bien incorporándose con un trámite concreto tras la notificación por parte de la Administración. En este punto, cabe advertir que el tema de la notificación es controvertido ya que constituye uno de los medios de comunicación entre la Administración y el sujeto interesado. Y cuando la notificación no ha tenido lugar o ha sido defectuosa (art. 44 de la vigente Ley 39/2015, de Procedimiento Administrativo), parece que si el interesado ha llevado a cabo las actuaciones correspondientes (por ejemplo, con la interposición de un recurso), la finalidad de la notificación queda cumplida. Sin embargo, esto no debería ser así ya que el conocimiento por parte del interesado del expediente administrativo no se puede presumir si no se ha producido la notificación.

39 SÁNCHEZ MORÓN, M., "Nuevas garantías de Derecho Administrativo", Revista de Administración Pública, 194, 2014, p. 279.

40 Ley 9/2017, de 8 de noviembre, de Contratos del Sector Público (arts. 44 y ss); Ley Orgánica 3/2013, de 20 de julio, sobre lucha contra el dopaje (art.40); Ley 19/2013, de 9 de diciembre, de Transparencia, Acceso a la Información Pública y Buen Gobierno (art. 24) y Ley 20/2013, de 9 de diciembre, de Garantía de la Unidad de Mercado. 
Este derecho de personación está íntimamente ligado al derecho de formular alegaciones y al derecho de audiencia. Parece que ambos derechos pueden resultar reñidos en el sentido que si el sujeto interesado ha hecho suyo el derecho a redactar alegaciones, se le ha posibilitado vías de poder dirigirse a la Administración y plantearle lo que le ha parecido pertinente. Sin embargo, considero que aunque esto haya ocurrido así, no se le puede privar de su derecho de audiencia, ya que con el trámite de alegaciones, el sujeto afectado se pronuncia sobre aspectos concretos del procedimiento con los que no esté totalmente de acuerdo y en un determinado momento del procedimiento. Pero puede que con posterioridad a ese trámite, se lleven a cabo otras actuaciones llevadas a cabo por la Administración y que el sujeto las desconozca. Y para el conocimiento completo de todas las actuaciones realizadas, de todo el expediente administrativo en definitiva, está configurado el trámite de audiencia. Por consiguiente, ambos trámites deben existir y complementarse ya que uno no sustituye al otro.

En este sentido, la proposición y la práctica de la prueba también están ligados al derecho de defensa de los interesados ya que la Administración no puede resolver un procedimiento sin tener en consideración los hechos que se han alegado y que han resultado probados de acuerdo a derecho.

Sin el respeto a todos estos derechos por parte del sujeto interesado, el resultado es la indefensión, algo completamente perjudicial para el sujeto afectado por una actuación de la Administración.

\section{El procedimiento administrativo como deber de la Administración y como garantía de defensa para las personas.}

El procedimiento administrativo se constituye como el cauce formal a través del cual se formaliza y concreta la actuación de la Administración respecto de un asunto concreto. Y supone para la Administración una obligación ya que sin ese procedimiento, no puede dictar una resolución ya que sería nula de pleno derecho. Y desde el punto de vista del ciudadano, la existencia de este procedimiento supone que desde que se inicia el mismo, por iniciativa del sujeto o por voluntad de la Administración, tiene diferentes momentos o trámites para ejercitar su derecho a la defensa mediante la presentación de alegaciones, proposición de prueba, trámite de vista y audiencia, etc.

El procedimiento administrativo se materializa en un expediente en el que se recogen todos los documentos y trámites que se han llevado a cabo que sirven de fundamento a la resolución administrativa que va a dictar la Administración. Es por ello, que el ciudadano afectado por la misma debe ir conociendo todas las actuacio- 
nes que la Administración realiza para poder tener en ese momento la oportunidad de defenderse ante la Administración.

El ciudadano es el interesado en el procedimiento administrativo ya que tal como establece el artículo 4 de la Ley 39/2015, “a) quienes lo promuevan como titulares de derechos o intereses legítimos individuales o colectivos; b) los que, sin haber iniciado el procedimiento, tengan derechos que puedan resultar afectados por la decisión que en el mismo se adopte; c) aquellos cuyos intereses legítimos, individuales o colectivos, puedan resultar afectados por la resolución y se personen en el procedimiento en tanto no haya recaído resolución definitiva”.

Es en el artículo 13 de esa misma Ley donde se regulan los derechos de las personas en sus relaciones con las Administraciones Públicas ${ }^{41}$. Si se compara este precepto con el equivalente en la ya derogada LRJPAC se deduce que en la vigente se distinguen, por un lado, los derechos de las personas y, por otro, los derechos de los interesados. De tal forma que en el artículo 13 se dispone que "a) A comunicarse con las Administraciones Públicas a través de un Punto de Acceso General electrónico de la Administración; b) a ser asistidos en el uso de medios electrónicos en sus relaciones con las Administraciones Públicas; c) a utilizar las lenguas oficiales en el territorio de su Comunidad Autónoma, de acuerdo con lo previsto en esta Ley y en el resto del ordenamiento jurídico; d) al acceso a la información pública, archivos y registros, de acuerdo con lo previsto en la Ley 19/2013, de 9 de diciembre, de transparencia, acceso a la información pública y buen gobierno y el resto del Ordenamiento Jurídico; e) a ser tratados con respeto y deferencia por las autoridades y empleados públicos, que habrán de facilitarles el ejercicio de sus derechos y el cumplimiento de sus obligaciones; f) a exigir las responsabilidades de las Administraciones Públicas y autoridades, cuando así corresponda legalmente; g) a la obtención y utilización de los medios de identificación y firma electrónica contemplados en esta Ley; h) a la protección de datos de carácter personal, y en particular a la seguridad y confidencialidad de los datos que figuren en los ficheros, sistemas y aplicaciones de las Administraciones Públicas; i) cualesquiera otros que les reconozcan la Constitución y las leyes".

41 Sobre las novedades respecto del procedimiento administrativo, véase a GALLARDO CASTILLO, M ${ }^{\mathrm{a}} \mathrm{J}$. (Dir.), Aproximación al nuevo procedimiento administrativo común de la Ley 39/2015: reflexiones y claves para su aplicación, ed. CEMCI, Madrid, 2016; GOSÁLBEZ PEQUEÑO, H., La nueva Ley de Procedimiento Administrativo Común, ed. El Consultor de los Ayuntamientos y los Juzgados, Madrid, 2016; GUTIÉRREZ COLOMINA, V., "La estructura del procedimiento administrativo común y especialidades", Revista de Estudios Locales, 191, 2016, pp. 160-190; "MARTÍNEZ GUTIÉRREZ, R., El régimen jurídico del nuevo procedimiento administrativo común, ed. Thomson-Reuters Aranzadi, Cizur Menor, 2016; RIVERO ORTEGA, R., Instituciones de Procedimiento Administrativo Común, ed. Marcial Pons, Madrid, 2016 y TORNOS MAS, J., Estudios sobre las Leyes 39/2015 del procedimiento administrativo común y 40/2015, del régimen jurídico del sector público, ed. Atelier, Madrid, 2017. 
Y el artículo 53 se refiere exclusivamente a las garantías que el interesado, es decir, el sujeto afectado por la actuación de la Administración, tiene respecto de ella:

“a) a conocer, en cualquier momento, el estado de la tramitación de los procedimientos en los que tengan la condición de interesados; el sentido del silencio administrativo que corresponda, en caso de que la Administración no dicte ni notifique resolución expresa en plazo; el órgano competente para su instrucción, en su caso, y resolución; y los actos de trámite dictados. Asimismo, también tendrán derecho a acceder y a obtener copia de los documentos contenidos en los citados procedimientos. Quienes se relacionen con las Administraciones Públicas a través de medios electrónicos, tendrán derecho a consultar la información a la que se refiere el párrafo anterior, en el Punto de Acceso General electrónico de la Administración que funcionará como un portal de acceso. Se entenderá cumplida la obligación de la Administración de facilitar copias de los documentos contenidos en los procedimientos mediante la puesta a disposición de las mismas en el Punto de Acceso General electrónico de la Administración competente o en las sedes electrónicas que correspondan; b) a identificar a las autoridades y al personal al servicio de las Administraciones Públicas bajo cuya responsabilidad se tramiten los procedimientos; c) a no presentar documentos originales salvo que, de manera excepcional, la normativa reguladora aplicable establezca lo contrario. En caso de que, excepcionalmente, deban presentar un documento original, tendrán derecho a obtener una copia autenticada de éste; d) a no presentar datos y documentos no exigidos por las normas aplicables al procedimiento de que se trate, que ya se encuentren en poder de las Administraciones Públicas o que hayan sido elaborados por éstas; e) a formular alegaciones, utilizar los medios de defensa admitidos por el Ordenamiento Jurídico, y a aportar documentos en cualquier fase del procedimiento anterior al trámite de audiencia, que deberán ser tenidos en cuenta por el órgano competente al redactar la propuesta de resolución; f) a obtener información y orientación acerca de los requisitos jurídicos o técnicos que las disposiciones vigentes impongan a los proyectos, actuaciones o solicitudes que se propongan realizar; g) a actuar asistidos de asesor cuando lo consideren conveniente en defensa de sus intereses; h) a cumplir las obligaciones de pago a través de los medios electrónicos previstos en el artículo 98.2; i) cualesquiera otros que les reconozcan la Constitución y las leyes. 2. Además de los derechos previstos en el apartado anterior, en el caso de procedimientos administrativos de naturaleza sancionadora, los presuntos responsables tendrán los siguientes derechos: a) A ser notificado de los hechos que se le imputen, de las infracciones que tales hechos puedan constituir y de las sanciones que, en su caso, se les pudieran imponer, así como de la identidad del instructor, de la autoridad competente para imponer la sanción y de la norma que atribuya tal competencia; b) a la presunción de no existencia de responsabilidad administrativa mientras no se demuestre lo contrario". 
Dentro de las novedades que ha introducido la nueva Ley de Procedimiento ${ }^{42}$, considero que uno de los aciertos puede haber sido la enumeración de los derechos que tiene el particular en general y el interesado en particular, ya que en lo que respecta al resto de modificaciones, ha sido más un cambio de sistemática y estructura más que auténticos cambios de fondo puesto que todo lo relativo a la administración electrónica, por ejemplo, ya había sido regulado por normas anteriores. El Consejo de Estado en su dictamen 275/2015 se pronuncia en estos términos:

"Resulta oportuno hacer notar que el contenido que presenta el anteproyecto es, en líneas generales y desde el punto de vista sustantivo, muy similar al de la vigente Ley 30/1992, en aquellos aspectos de ésta que han quedado incluidos en este proyecto normativo, o, en su caso, prácticamente idéntico al de la Ley 11/2007, en lo relativo al uso de medios electrónicos, incorporando, además, numerosas previsiones actualmente contenidas en las correspondientes normas reglamentarias de desarrollo. En efecto, aun cuando ciertamente la regulación actual se innova en algunos puntos concretos -cabe, por ejemplo y sin ánimo exhaustivo, mencionar el cómputo de los plazos por horas, la extensión al sábado de la condición de día inhábil a efectos de cómputo de plazos, la regulación de la responsabilidad patrimonial del Estado legislador, la eliminación del plazo de 3 meses para la impugnación de actos presuntos, el establecimiento de un plazo de 6 meses para los procedimientos de revisión de oficio o la regulación ex novo del procedimiento abreviado, novedades todas éstas a las que han de sumarse las que afectan a la llamada Administración electrónica y la regulación del procedimiento de elaboración de normas-, no pasa desapercibido que la mayoría de los preceptos del anteproyecto reproducen, a veces con ligeras modificaciones, el contenido de las normas que en la actualidad regulan las materias que constituyen su objeto. En realidad, la verdadera innovación de la regulación proyectada radica, como se ha indicado, en el enfoque que inspira la iniciativa, que se traduce en un vuelco sistemático".

El procedimiento administrativo opera como garantía de legalidad ya que la base de la seguridad jurídica, en base al artículo 9.3 de la Constitución es el procedimiento. Toda modificación en una norma o una actuación administrativa es posible pero sólo si se lleva a cabo cumpliendo y respetando un procedimiento en el que se materialicen los trámites que se llevan a cabo y que son sólo esos los que se van a realizar. De otra forma, se produciría una clara inseguridad jurídica. Lo que

42 CAMPOS ACUÑA, Ma C., El nuevo procedimiento administrativo local tras la Ley 39/2015, ed. Wolters Kluwer, 2016; FERNÁNDEZ FARRERES, G., "El procedimiento administrativo común en la nueva Ley 39/2015, de 1 de octubre: novedades y algunas cuestiones problemáticas", Cuadernos de Derecho Local, 41, 2016, pp. 14-49 y GALLARDO CASTILLO, Mª J. (Dir.), Aproximación al nuevo procedimiento administrativo común de la Ley 39/2015: reflexiones y claves para su aplicación, ed. Centro de Estudios Municipales y de Cooperación Interprovincial, 2016. 
preserva de la arbitrariedad es la observancia de las formas. Y esto es básico, no da lugar a interpretaciones.

CASTILLO BLANCO afirma que "el principio de buena fe, en toda la amplitud de su contenido, requiere, al menos en mayor medida que el principio de protección de confianza, un plano de igualdad en las relaciones y un fraude en éstas debido a una actuación torcida de una de las partes. No son así, como sabemos, las relaciones de la Administración con los ciudadanos, donde el servicio objetivo y eficaz a los intereses generales (art. $103 \mathrm{CE}$ ) dota a ésta de potestades y no solamente de derechos...no quiere decir que la Administración pueda actuar arbitrariamente frente a los ciudadanos, ni defraudar la confianza de éstos, ni actuar de una forma sorpresiva... No es el principio de buena fe el que protege dichas relaciones, sino un principio de mayor relevancia constitucional y más propia de la posición institucional de la Administración pública: la seguridad jurídica, que tiene su manifestación en estos concretos aspectos a través del principio de protección de confianza que se ajusta de esa forma a las relaciones de la Administración con los ciudadanos"43.

Como establece la STS de 22 de septiembre de 1990, "el procedimiento administrativo no es un mero ritual tendente a cubrir a un poder desnudo con una vestidura pudorosa que evite el rechazo social. Que no se trata de cubrir impudicias sino de que nos las haya. Porque lo que exige el pudor en las relaciones entre el poder público y los ciudadanos es que el comportamiento de aquél inspire confianza a los administrados" ${ }^{\prime 4}$.

\section{El silencio administrativo: ¿una garantía para las personas?}

El legislador concibe el silencio administrativo como una garantía para el interesado afectado por una actuación de la Administración. Y considero que esta concepción es errónea. Porque lo que es en realidad es un incumplimiento por parte de la Administración de su obligación por resolver, es decir, la Administración tiene un plazo para resolver y concluido el mismo, no dicta resolución. Cuando esa no respuesta es un silencio negativo, el ciudadano entiende que es como si la Administración hubiera dictado una resolución desestimatoria, es decir, como si la Administración le dijera que no a su pretensión. Y es en ese caso, cuando surge la ficción jurídica de crear un acto ficticio con el objetivo de que el ciudadano tenga una base o soporte sobre el que fundamentar su recurso.

En consecuencia, ese silencio no es una garantía para las personas, es un remedio, permítaseme la expresión, para la Administración, ya que se le permite a la

43 CAStillo BLANCO, F., La protección de confianza en el Derecho Administrativo, ed. Marcial Pons, Madrid, 1998, pp. 273-274.

$44 \quad$ RJ $1990 \backslash 7285$. 
Administración no cumplir con su obligación, puesto que la garantía o el derecho que tiene la persona es que la Administración instruya y resuelva el procedimiento y se pronuncie sobre si procede o $\mathrm{no}^{45}$.

Lo que considero es que no debe normalizarse esta vía del silencio ya que lo que debe ser es que la Administración resuelva en plazo. Como expone BAÑO LEÓN, si la Administración ha incumplido con su obligación esencial de contestar, esa infracción no puede acarrear "la obligación del ciudadano de recurrir so pena de consentir un acto inexistente" ${ }^{\prime 4}$.

Y en los supuestos donde la inactividad de la Administración da lugar a un silencio positivo, es decir, como si hubiera dictado una resolución estimatoria, es la regla general en los procedimientos iniciados a instancia de parte y esto tampoco parece razonable. En todo caso, este silencio también debe aceptarse en supuestos excepcionales y que la Ley los enumere de forma clara pero no como regla general.

En este sentido, cabe referirse a la STS de 15 de septiembre de 2004, que establece que "no cabe duda que por la vía del silencio no pueden obtenerse facultades, ya sean públicas o privadas, contrarias al ordenamiento jurídico...lo que equivaldría, además, a una transferencia de facultades públicas imposibles de obtener por vía de silencio (art. 43.2.b). En segundo término, porque la falta de resolución en el plazo legal no genera siempre una estimación de la petición, y esto, tanto se efectúe por un particular como por otra Administración, ya que la naturaleza pública de ésta podrá afectar al régimen jurídico del proceso, pero no a sus derechos materiales...En tercer lugar, porque muchas de las peticiones debieron realizarse durante el período de información pública de los proyectos de obras, de tal forma que las reclamaciones que fueron realizadas en este período se ha de entender que no fueron acogidas si a ellas no se atendieron en la aprobación del proyecto, y sería éste el que tuvo que ser recurrido" ${ }^{47}$.

${ }^{4}$ ALONSO IBÁÑEZ, M. R., "El incumplimiento de la obligación de resolver", en el vol. col. QUINTANA LÓPEZ, T. y CASARES MARCOS, A. B. (Coords.), Silencio administrativo. Estudio general y procedimientos especiales, ed. Tirant Lo Blanch, 2012, pp. 185-273; BAÑO LEÓN, J. M., "El silencio administrativo: notas sobre un regulación anacrónica", en el vol. col. SOSA WAGNER, F. (Coord.), El Derecho Administrativo en el umbral del siglo XXI: homenaje al Prof. Dr. D. Ramón Martín Mateo, vol. I, ed. Tirant Lo Blanch, 2000, pp. 1343-1364; GÓMEZ PUENTE, M., "El silencio y la inactividad de la Administración", en el vol. col. QUINTANA LÓPEZ, T. y CASARES MARCOS, A. B. (Coords.), Silencio administrativo. Estudio general y procedimientos especiales, ed. Tirant Lo Blanch, 2012, pp. 23-134; PAREJO ALFONSO, L., El silencio en la actividad de la Administración Pública, ed. Tirant Lo Blanch, 2011 y RIVERO YSERN, R., "Obligación de resolver y silencio administrativo", en el vol. col. RIVERO ORTEGA, R., CALVO SÁNCHEZ, M. D. y FERNANDO PABLO, M. M. (Dirs.), Instituciones de procedimiento administrativo común: novedades de la Ley 39/2015 del Procedimiento Administrativo Común de las Administraciones Públicas, ed. Juruá, 2016, pp. 151-176.

46 BAÑO LEÓN, J. M., "El silencio administrativo: notas sobre un regulación anacrónica", cit., p. 1349 .

$47 \quad$ RJ 2004\5830. 
MENÉNDEZ REXACH igualmente expone que "la inactividad no puede perjudicar a los interesados, en cuanto presupone el incumplimiento por la Administración de su obligación de resolver. Eso tiene una consecuencia práctica muy importante: cuando el silencio es negativo, la Administración no puede invocar la firmeza del acto presunto, por no haber sido recurrido por el particular, sino que éste puede recurrir en cualquier tiempo sin plazo preclusivo para ello" ${ }^{48}$.

La STS de 2 de octubre de 1997 se refería al silencio administrativo en estos términos: "Así en la Sentencia de 18 marzo 1995, se dice que del hecho de que la Administración vulnere el ordenamiento jurídico infringiendo su deber de resolver expresamente las peticiones y recursos de parte, ningún menoscabo puede derivarse para el derecho a la tutela judicial efectiva del administrado, ya que, en definitiva, al ser el acto denegatorio presunto por silencio una ficción legal introducida en beneficio del administrado y no existir, por tanto, acto administrativo propiamente dicho, no puede aplicarse al mismo la calificación de consentido, por razón del tiempo transcurrido y de definitivamente inimpugnable; sin olvidar, tampoco, que no es razonable primar la inactividad de la Administración, colocándola en mejor situación que si hubiera resuelto y notificado la resolución reglamentariamente" ${ }^{\$ 4}$.

La Sentencia de 28 octubre $1996^{50}$, ha recordado una reiterada doctrina de esta Sala que ha venido a establecer que el silencio no es una opción para que la Administración pueda elegir entre resolver expresamente o no hacerlo, sino una garantía para los administrados frente a la pasividad de los órganos obligados a resolver, garantía de la que se puede hacer uso o esperar a la resolución expresa sin que ello pueda comportar en principio ningún perjuicio al interesado.

Por otra parte, dice también la sentencia citada, el silencio tampoco es un acto administrativo sino una ficción jurídica que deviene innecesaria cuando se produce, aunque sea con retraso, la resolución expresa, reabriéndose con ella el plazo para el recurso jurisdiccional, que no cerró la prolongación del precedente silencio de la Administración.

Dando un paso más la expresada sentencia llega a decir «pero es que, además, a la expresa resolución desestimatoria debidamente notificada, aunque sea de forma tardía, ha de equipararse cualquier actuación de la Administración incursa en la mora tendente a ejecutar el acto recurrido, con lo que la presunción desestimatoria se confirma». Doctrina de esta Sala que se apoya expresamente en la Sentencia del

48 MENÉNDEZ REXACH, A., "El control jurisdiccional de la inactividad de la Administración", Anuario de la Facultad de Derecho de la Universidad Autónoma de Madrid, 5, 2001, pp. 163-186.

49 RJ 1997\7742.

$50 \quad$ RJ 1996\9582. 
Tribunal Constitucional núm. 6 de 21 enero 1986 y que puede delimitarse diciendo que ante la falta de resolución expresa de la Administración, en el caso de silencio negativo, el interesado puede optar por tener por denegada su pretensión y ejercitar los recursos pertinentes en los plazos legalmente establecidos, contados desde que se presume producida la denegación, o bien, esperar a que la Administración se pronuncie, ya lo haga cumpliendo sus obligaciones y resolviendo expresamente, aunque lo sea con retraso, o simplemente vuelva a confirmar tácitamente aquella primera denegación presunta, intentando ejecutar, incluso de manera simplemente fáctica, al acuerdo ficticiamente adoptado, abriéndose de nuevo, en ambos casos, todos los plazos para su impugnación”.

La STG 220/2003, de 15 de diciembre en relación al silencio administrativo señala que "la Administración no puede verse beneficiada por el incumplimiento de su obligación de resolver expresamente en plazo solicitudes de los ciudadanos, pues este deber entronca con la cláusula del Estado de Derecho (art. 1.1 CE), así como con los valores que proclaman los arts. 24.1, 103.1 y 106.1 CE. Por este motivo, hemos dicho también que el silencio administrativo de carácter negativo se configura como «una ficción legal que responde a la finalidad de que el administrado pueda, previos los recursos pertinentes, llegar a la vía judicial superando los efectos de inactividad de la Administración», de manera que, en estos casos, no puede calificarse de razonable aquella interpretación de los preceptos legales «que prima la inactividad de la Administración, colocándola en mejor situación que si hubiera cumplido su deber de resolver» [SSTC 6/1986, de 21 de enero; 204/1987, de 21 de diciembre; 180/1991, de 23 de septiembre. Así, con base en la anterior doctrina hemos concluido que «[si el silencio negativo es una institución creada para evitar los efectos paralizantes de la inactividad administrativa, es evidente que ante una resolución presunta de esta naturaleza el ciudadano no puede estar obligado a recurrir, siempre y en todo caso, so pretexto de convertir su inactividad en consentimiento con el acto presunto, exigiéndosele un deber de diligencia que no le es exigido a la Administración. Deducir de ese comportamiento pasivo - que no olvidemos, viene derivado de la propia actitud de la Administración - un consentimiento con el contenido de un acto administrativo que fue impugnado en tiempo y forma, supone una interpretación absolutamente irrazonable desde el punto de vista del derecho de acceso a la jurisdicción, como contenido esencial del derecho a la tutela judicial efectiva previsto en el art. 24.1 CE, pues no debemos descuidar que la Ley no obliga al ciudadano a recurrir un acto presunto y sí a la Administración a resolver, de forma expresa, el recurso presentado» (F. 6)".

Lo que la nueva Ley de Procedimiento ha establecido al respecto del silencio creo que es un acierto y hasta la entrada en vigor de la misma, era un tema que suscitaba críticas. Me refiero a que ahora el interesado en recurrir un silencio negativo en vía administrativa ya no tiene el plazo de 3 meses que tenía con la LRJPAC (en el caso del 
recurso de alzada, "si el acto no fuera expreso el solicitante y otros posibles interesados podrán interponer recurso de alzada en cualquier momento a partir del día siguiente a aquel en que, de acuerdo con su normativa específica, se produzcan los efectos del silencio administrativo" (art. 122.1) y en el caso del recurso de reposición, "si el acto no fuera expreso, el solicitante y otros posibles interesados podrán interponer recurso de reposición en cualquier momento a partir del día siguiente a aquel en que, de acuerdo con su normativa específica, se produzca el acto presunto" (art. 124.1).

Y esto parece que es ventajoso para el interesado ya que hasta ahora como la Administración tiene la obligación de resolver y notificar, lo decisivo era la notificación ya que a partir de ese momento, el interesado podía recurrir. Y en caso de silencio, desde que éste tuviera efectos. En esos casos, parece que tenía que ser el recurrente quien determinara el momento en el que quería hacer efectivo el juego del silencio administrativo siempre que la Administración no resolviera. De esa manera, parece que se cumplía el principio de tutela judicial efectiva.

Parece que el legislador ha recapacitado y ha suprimido el obstáculo procesal de cumplir un determinado plazo para impugnar el silencio negativo. Y el empeño del legislador debiera ser el que la Administración resuelva en cada procedimiento, incluso obviando la regulación del silencio como forma de terminación del procedimiento administrativo. Sí que el legislador ha dedicado un precepto a la obligación de resolver por parte de la Administración en el artículo 21, pero resulta una obligación leve ya que no se prevé ningún tipo de consecuencia si no la cumple.

En el artículo 53 de la nueva Ley de Procedimiento, el legislador ha perdido la oportunidad de incorporar como un derecho del interesado en el procedimiento administrativo, el derecho a que la Administración resuelva todos los procedimientos que se inicien, bien a instancia del sujeto o bien por propia voluntad de la Administración. No sólo que instruya el procedimiento dando cumplimiento al principio de impulsión de oficio sino que una vez realizados los actos de instrucción, dicte una resolución. Sin embargo, esto no se ha producido con la nueva Ley.

\section{El principio de confianza legítima como garantía de igualdad.}

Se trata de un principio de suma importancia en nuestro ordenamiento jurídico pero que en la nueva Ley de Procedimiento de 2015, sorprendentemente, ya no aparece regulado ${ }^{51}$. Por el contrario, donde sí se regula es en la Ley 40/2015, del

$51 \quad$ El principio de buena fe o confianza legítima tiene su origen en el Derecho Administrativo alemán (Sentencia de 14 de mayo de 1956 del Tribunal Contencioso-Administrativo de Berlín), y, desde las Sentencias del Tribunal de Justicia de la Comunidad Europea de 22 de marzo de 1961 y 13 de julio de 1965 
Sector público en su artículo 3 donde se regulan los principios generales que deben inspirar la actuación de la Administración pública ${ }^{52}$. Nuevamente, surge aquí el debate sobre la conveniencia o no de las dos leyes, la 39 y la 40, ya que en muchos casos, como el que acabo de reseñar, obedece a error. ¿Por qué este precepto dedicado a los principios inspiradores de la actuación de la Administración no aparece en la Ley 39/2015? ¿Siendo la Ley 39/2015 la ley que regula el procedimiento administrativo, no hubiera tenido sentido incorporar también los principios que rige su actuación? Al final, esta doble regulación da lugar a confusión.

El citado principio rige las relaciones entre las personas y la Administración en un Estado social y democrático de Derecho y proporciona el marco de actuación de los particulares en sus relaciones con los poderes públicos administrativos, caracterizado por las notas de previsibilidad y seguridad jurídica, contempladas en los artículos $9^{53}$ y $103^{54}$ de la Constitución.

(asunto Lemmerz-Werk), constituye un principio general del Derecho Comunitario, que finalmente fue acogido por nuestro Tribunal Supremo desde 1990 y también por nuestra legislación (en concreto, por la Ley 4/1999 de reforma de la Ley 30/1992, de Régimen de las Administraciones Públicas y del Procedimiento Administrativo Común en su artículo 3.1.2.

52 Las Administraciones Públicas sirven con objetividad los intereses generales y actúan de acuerdo con los principios de eficacia, jerarquía, descentralización, desconcentración y coordinación, con sometimiento pleno a la Constitución, a la Ley y al Derecho. Deberán respetar en su actuación y relaciones los siguientes principios:

a) Servicio efectivo a los ciudadanos.

b) Simplicidad, claridad y proximidad a los ciudadanos.

c) Participación, objetividad y transparencia de la actuación administrativa.

d) Racionalización y agilidad de los procedimientos administrativos y de las actividades materiales de gestión.

e) Buena fe, confianza legítima y lealtad institucional.

f) Responsabilidad por la gestión pública.

g) Planificación y dirección por objetivos y control de la gestión y evaluación de los resultados de las políticas públicas.

h) Eficacia en el cumplimiento de los objetivos fijados.

i) Economía, suficiencia y adecuación estricta de los medios a los fines institucionales.

j) Eficiencia en la asignación y utilización de los recursos públicos.

k) Cooperación, colaboración y coordinación entre las Administraciones Públicas

53 Artículo 9 GE: 1. Los ciudadanos y los poderes públicos están sujetos a la Constitución y al resto del ordenamiento jurídico. 2. Corresponde a los poderes públicos promover las condiciones para que la libertad y la igualdad del individuo y de los grupos en que se integra sean reales y efectivas; remover los obstáculos que impidan o dificulten su plenitud y facilitar la participación de todos los ciudadanos en la vida política, económica, cultural y social. 3. La Constitución garantiza el principio de legalidad, la jerarquía normativa, la publicidad de las normas, la irretroactividad de las disposiciones sancionadoras no favorables o restrictivas de derechos individuales, la seguridad jurídica, la responsabilidad y la interdicción de la arbitrariedad de los poderes públicos.

54 1. La Administración Pública sirve con objetividad los intereses generales y actúa de acuerdo con los principios de eficacia, jerarquía, descentralización, desconcentración y coordinación, con someti- 
Dicho principio rector de la actuación de las Administraciones Públicas expresa la confianza de las personas en que la actuación de las Administraciones Públicas no puede ser alterada arbitrariamente.

La Sentencia del Tribunal Supremo de 1 de febrero de 1999 recuerda que "este principio no puede invocarse para crear, mantener o extender, en el ámbito del Derecho público, situaciones contrarias al ordenamiento jurídico, o cuando del acto precedente resulta una contradicción con el fin o interés tutelado por una norma jurídica que, por su naturaleza, no es susceptible de amparar una conducta discrecional por la Administración que suponga el reconocimiento de unos derechos y/u obligaciones que dimanen de actos propios de la misma. O, dicho en otros términos, la doctrina invocada de los «actos propios» sin la limitación que acaba de exponerse podría introducir en el ámbito de las relaciones de Derecho público el principio de la autonomía de la voluntad como método ordenador de materias reguladas por normas de naturaleza imperativa, en las que prevalece el interés público salvaguardado por el principio de legalidad; principio que resultaría conculcado si se diera validez a una actuación de la Administración contraria al ordenamiento jurídico por el solo hecho de que así se ha decidido por la Administración o porque responde a un precedente de ésta.

Una cosa es la irrevocabilidad de los propios actos declarativos de derechos fuera de los cauces de revisión establecidos en la Ley (artículos 109 y 110 de la Ley de Procedimiento Administrativo de 1958, 106 y 107 de la Ley 9/2015, de 1 de octubre, del Procedimiento Administrativo Común de las Administraciones Públicas) y otra el respeto a la confianza legítima generada por actuación propia que necesariamente ha de proyectarse al ámbito de la discrecionalidad o de la autonomía, no al de los aspectos reglados o exigencias normativas frente a las que, en el Derecho Administrativo, no puede prevalecer lo resuelto en acto o en precedente que fuera contrario a aquéllos. $\mathrm{O}$, en otros términos, no puede decirse que sea legítima la confianza que se deposite en un acto o precedente que sea contrario a norma imperativa" ${ }^{55}$.

GONZÁLEZ PÉREZ, al referirse a los efectos del principio de confianza legítima, señala que actúa como límite al ejercicio de las potestades administrativas, citando la sentencia del Tribunal Supremo de 7 de octubre de $1991^{56}$ en la que se enjuicia un supuesto en el que la Administración difundió un escrito al sector econó-

miento pleno a la ley y al Derecho. 2. Los órganos de la Administración del Estado son creados, regidos y coordinados de acuerdo con la ley. 3. La ley regulará el estatuto de los funcionarios públicos, el acceso a la función pública de acuerdo con los principios de mérito y capacidad, las peculiaridades del ejercicio de su derecho a sindicación, el sistema de incompatibilidades y las garantías para la imparcialidad en el ejercicio de sus funciones.

$55 \quad$ RJ $1999 \backslash 1633$.

$56 \quad$ RJ $1991 \backslash 7520$. 
mico interesado, en el que se anunciaban los criterios a seguir en un Plan de Reestructuración Industrial, "que si bien no eran jurídicamente vinculantes en el sentido propio del concepto sí representan unos actos externos propios de la Administración, a tener en cuenta el principio constitucional de la "seguridad jurídica" que no puede defraudar el principio jurisprudencial de la "confianza legítima del administrado", proclamado por el Tribunal de la Comunicad Europea y asumido por la jurisprudencia de esta Sala que ahora enjuicia".

Los efectos que produce este principio son que supone un límite al ejercicio de las potestades administrativas. Asimismo, constituye una garantía de la igualdad de trato de las personas por las Administraciones públicas y que éstas no pueden defraudar las esperanzas de las personas y que si se frustran las expectativas legítimas generadas a favor de ellos, se deben resarcir.

En esta misma línea, el Tribunal Supremo ha establecido en diversas sentencias esa misma opinión ya que ha establecido que la confianza del interesado es legítima cuando la Administración lleva a cabo actuaciones concluyentes para que aquél pueda razonablemente entender. Se refiere a que la Administración actúe correctamente (STS de 23 de noviembre de $1984^{57}$ ), a que sus expectativas como interesado sean razonables (STS de 28 de febrero de $1989^{58}$ ) y a que el interesado haya cumplido sus obligaciones que en cada caso tenga (STS de 30 de junio de $1993^{59}$ ).

\section{REFLEXIÓN FINAL.}

Mi intención en este artículo ha sido la del estudio de la figura del ciudadano o administrado en el Derecho Administrativo, ya que considero que no se le da el lugar que merece. Como ya se ha dicho, sin personas la Administración no tiene destinatario de sus medidas y actuaciones. Sin él, carece de sentido por completo hablar de Administración Pública.

La segunda idea que quiero destacar es que si la actuación de cualquier Administración es la de perseguir el interés general o el interés público, nuevamente nos topamos con el ciudadano y su beneficio. Los servidores de la Administración no pueden orientar su actuación para su propio beneficio o el beneficio de unos pocos, sino que debe ser el mayor número de población el que resulte beneficiado por la misma. Nuevamente aquí se resalta la figura del ciudadano/persona. 
Como tercera reflexión, el Estado ha evolucionado hacia un Estado garante, es decir, un Estado que debe velar porque los prestadores de los servicios, que antes eran prestados por él, se lleven a cabo y también en las mejores condiciones posibles. Debe garantizar que éstos se materialicen en las mismas condiciones que si estuvieran gestionados o prestados por la Administración. Ya no se habla de Estado regulador, donde la persona asume una posición pasiva respecto de las prerrogativas de la Administración sino que estamos ante un Estado garante, donde el sujeto interfiere y se sitúa en una posición activa y reivindicativa, cuando procede, ante la Administración.

Y como última reflexión para concluir, destaco la oportunidad perdida por parte de la nueva Ley de Procedimiento y también de la nueva Ley del Sector Público de haber destacado la figura de las personas como sujeto de Derecho y sus garantías. Además de la crítica que se le puede hacer a estas dos leyes respecto a que ha sido más un cambio de estructura y orden de las mismas más que una auténtica modificación en su contenido. Es cierto que la incorporación de todo lo relacionado con la Administración electrónica es muy novedosa pero no en cuanto a su contenido ya que anteriormente había ya normas que lo regulaban.

Por otro lado, es cierto que ha habido modificaciones respecto de aspectos concretos, tal como he citado anteriormente, pero a mi entender no creo que sean leyes que sitúen a la persona como centro y sentido de esas normas y esto es lo que debiera ser. En definitiva, ¿se encuentra la persona más protegida o con más garantías ante la Administración con las nuevas Leyes de Procedimiento y de Sector Público? Mi respuesta es que no y se supone que las modificaciones legislativas debieran perseguir dicho fin. Concluyo con la frase que cito al principio, "hominis causa omne ius constitutu est" (el Derecho está al servicio de las personas") y en lo que respecta al Derecho Administrativo, las personas son las que dan sentido, las que fundamentan la existencia de la Administración, no nos olvidemos de eso. 


\section{BIBLIOGRAFÍA.}

- ALONSO IBÁÑEZ, M. R., "El incumplimiento de la obligación de resolver", en el vol. col. QUINTANA LÓPEZ, T. y CASARES MARCOS, A. B. (Coords.), Silencio administrativo. Estudio general y procedimientos especiales, ed. Tirant Lo Blanch, 2012, pp. 185-273.

- BAENA DE ALCÁZAR, M., "Sobre la idea europea de buena administración", Noticias de la Unión Europea, 247-248, 2005, pp. 61- 66.

- BAÑO LEÓN, J. M., "El silencio administrativo: notas sobre un regulación anacrónica", en el vol. col. SOSA WAGNER, F. (Coord.), El Derecho Administrativo en el umbral del siglo XXI: homenaje al Prof. Dr. D. Ramón Martín Mateo, vol. I, ed. Tirant Lo Blanch, 2000, pp. 1343-1364.

- GALVO SÁNCHEZ, Ma D., "Objetivos de la reforma. Ámbito de aplicación. Principios rectores. Derechos de las personas y derechos de los interesados", en el vol. col. GALLARDO CASTILLO, $\mathrm{M}^{\mathrm{a}} \mathrm{J}$. (Dir.), Aproximación al nuevo procedimiento administrativo común de la Ley 39/2015: reflexiones y claves para su aplicación, ed. Centro de Estudios Municipales y de Cooperación Interprovincial, Madrid, 2016, pp. 19-77.

- CAMPOS ACUÑA, Ma C., El nuevo procedimiento administrativo local tras la Ley 39/2015, ed. Wolters Kluwer, 2016.

- CARRO FERNÁNDEZ-VALMAYOR, J. L., "Reflexiones sobre las transformaciones actuales del Derecho Público, en especial del Derecho Administrativo", Revista de Administración Pública, 193, 2014, pp. 11-44.

- CASTILLO BLANCO, F., La protección de confianza en el Derecho Administrativo, ed. Marcial Pons, Madrid, 1998.

- DABIN, J. (ed. MONEREO PE’REZ, J. L.), El derecho subjetivo, ed. Marcial Pons, Madrid, 2006.

- ESCRIBANO COLLADO, P., "Reflexiones sobre la indefensión en el procedimiento administrativo", en el vol. col. MARTÍN-RETORTILLO BAQUER, L. (Coord.), La protección jurídica del ciudadano: (procedimiento administrativo y garantía constitucional): estudios en homenaje al profesor Fesús González Pérez, ed. Civitas, Madrid, 1993, pp. 537-552.

- ESTEVE PARDO, J., La nueva valoración entre Estado y sociedad, ed. Marcial Pons, Madrid, 2013.

- ESTEVE PARDO, J., Lecciones de Derecho administrativo, ed. Marcial Pons, Madrid, 2015. 
- ESTEVE PARDO, J., “La Administración garante. Una aproximación”, $R e^{-}$ vista de Administración Pública, 197, 2015, pp. 11-39.

- ESTEVE PARDO, J., Autorregulación. Génesis y efectos, ed. Aranzadi, Cizur Menor, 2002 y DARNAGULLETA I GARDELLA, M., "Autorregulación normativa y derecho a la globalización”, en el vol. col. DARNAGULLETA I GARDELLA, M., ESTEVE PARDO, J. y SPIECKER GEN. GÖHMANN, I. (Eds.), Estrategias del Derecho ante la incertidumbre y la globalización, ed. Marcial Pons, Madrid, 2015, pp. 197-216.

- FERNÁNDEZ FARRERES, G., "El procedimiento administrativo común en la nueva Ley 39/2015, de 1 de octubre: novedades y algunas cuestiones problemáticas", Cuadernos de Derecho Local, 41, 2016, pp. 14-49.

- FERNÁNDEZ RODRÍGUEZ, T. R., "Reflexiones sobre la utilidad de la vía administrativa de recurso", Documentación Administrativa, 221, 1990, pp. 5-12.

- FREEMAN, J., "Collaborative gobernance in the administrative state", UCLA Law Review, 45, 1997, pp. 1-99.

- GALLARDO CASTILLO, M ${ }^{\mathrm{a}} \mathrm{J}$. (Dir.), Aproximación al nuevo procedimiento administrativo común de la Ley 39/2015: reflexiones y claves para su aplicación, ed. Centro de Estudios Municipales y de Cooperación Interprovincial, Madrid, 2016.

- GARCÍA PELAYO, M., Las transformaciones del Estado contemporáneo, ed. Alianza, Madrid, 1977 y PAREJO ALFONSO, L., "Estado y proceso de cambio. Del Estado prestacional al garante de la prestación", Asamblea: Revista Parlamentaria de la Asamblea de Madrid, 33, 2015, pp. 73-98.

- GÓMEZ PUENTE, M., "El silencio y la inactividad de la Administración", en el vol. col. QUINTANA LÓPEZ, T. y CASARES MARCOS, A. B. (Coords.), Silencio administrativo. Estudio general y procedimientos especiales, ed. Tirant Lo Blanch, 2012, pp. 23-134.

- GONZÁLEZ PÉREZ, J., "El administrado”, Revista Crítica de Derecho Inmobiliario, 452, 1966, pp. 9-64.

- GOSÁlBEZ PEQUEÑO, H., La nueva Ley de Procedimiento Administrativo Común, ed. El Consultor de los Ayuntamientos y los Juzgados, Madrid, 2016.

- GUILLEM CARRAU, J., "La buena administración en la Unión Europea tras el Tratado de Lisboa: ¿Más por menos?", Corts: Anuario de Derecho Parlamentario, 25, 2011, pp. 69-103.

- GUTIÉRREZ COLOMINA, V., "La estructura del procedimiento administrativo común y especialidades", Revista de Estudios Locales, 191, 2016, pp. 160-190. 
- HUERGO LORA, A. J., "Las leyes 39 y 40/2015. Su ámbito de aplicación y la regulación de los actos administrativos", El Cronista del Estado Social y Democrático de Derecho, 63, 2016, pp. 4-13.

- LAGUNA DE PAZ, J. C., "Regulación, externalización de actividades administrativas y autorregulación”, Revista de Administración Pública, 185, 2011, pp. 89-112.

- LÓPEZ MENUDO, F. (Coord.), Derechos y garantías del ciudadano: estudios en homenaje al profesor Alfonso Pérez Moreno, ed. Iustel, 2011.

- MARTÍN REBOLLO, L., "La Administración de garantías: vigencia y limitaciones", Revista del Centro de Estudios Constitucionales, 13, 1992, pp. 31-54.

- MARTÍN REBOLLO, L., "El procedimiento como garantía (una reflexión sobre el fortalecimiento de las formas y la reducción de los principios)", en el vol. col. LÓPEZ MENUDO, F. (Dir.), Derechos y garantías del ciudadano, ed. Iustel, Madrid, 2011, pp. 787-796.

- MARTÍNEZ GUTIÉRREZ, R., El régimen jurídico del nuevo procedimiento administrativo común, ed. Thomson-Reuters Aranzadi, Cizur Menor, 2016.

- MARTÍNEZ LÓPEZ-MUÑIZ, J. L., "La garantía constitucional del Derecho Administrativo", en el vol. col. BALADO, M. y GARCÍA REGUERO, J. A., La Constitución Española de 1978 en su XXV aniversario, ed. Bosch, Madrid, 2003, pp. 17-27.

- MARTÍN-RETORTILLO BÁCQUER, L., "Dos notas sobre la Carta", en GARGÍA DE ENTERRÍA, E. y ALONSO GARCÍA, R., La encrucijada constitucional de la Unión Europea, ed. Civitas, Madrid, 2002, pp. 183-198.

- MELLADO RUIZ, L., "Principio de buena administración y aplicación indirecta del derecho comunitario: instrumentos de garantía frente a la "comunitarización” de los procedimientos", Revista Española de Derecho Europeo, 27, 2008, pp. 281-325.

- MENÉNDEZ REXACH, A., "El control jurisdiccional de la inactividad de la Administración", Anuario de la Facultad de Derecho de la Universidad Autónoma de Madrid, 5, 2001, pp. 163-186.

- MONTIEL, F., "El ciudadano y el administrado", Revista de Administración Pública, 48, 1965, pp. 127-142.

- NOVAK, N. J., "Public-private gobernance: a historical introduction", en FREEMAN, J. \& MINOW, M. (eds.), Government by contract, ed. Harvard University Press, Cambridge, 2009. 
- PAREjO ALFONSO, L., El silencio en la actividad de la Administración Pública, ed. Tirant Lo Blanch, 2011.

- PAREJO ALFONSO, L., "Estado y proceso de cambio. Del Estado prestacional al garante de la prestación", Asamblea: Revista Parlamentaria de la Asamblea de Madrid, 33, 2015, pp. 73-98.

- PONCE SOLÉ, J., El principio de buena administración: discrecionalidad y procedimiento administrativo, ed. Universitat de Barcelona, Barcelona, 2001.

- RIVERO ORTEGA, R., El Estado vigilante. Consideraciones jurídicas sobre la función inspectora de la Administración, ed. Tecnos, Madrid, 2000.

- RIVERO ORTEGA, R., Instituciones de Procedimiento Administrativo Común, ed. Marcial Pons, Madrid, 2016.

- RIVERO YSERN, R., "Obligación de resolver y silencio administrativo", en el vol. col. RIVERO ORTEGA, R., GALVO SÁNCHEZ, M. D. y FERNANDO PABLO, M. M. (Dirs.), Instituciones de procedimiento administrativo común: novedades de la Ley 39/2015 del Procedimiento Administrativo Común de las Administraciones Públicas, ed. Juruá, 2016, pp. 151-176.

- RODRÍGUEZ ARANA MUÑOZ, J., El buen gobierno y la buena administración de las instituciones públicas, ed. Thomson Aranzadi, Cizur Menor, 2006.

- SÁNCHEZ BLANCO, A., "Del supraconcepto de administrado a la concreción constitucional de colectivos sociales", en el vol. col. MARTÍN-RETORTILLO BAQUER, L. (Coord.), La protección jurídica del ciudadano: (procedimiento administrativo y garantía constitucional): estudios en homenaje al profesor fesús González Pérez, ed. Civitas, Madrid, 1993, pp. 341-354.

- SÁNCHEZ MORÓN, M., "Nuevas garantías de Derecho Administrativo", Revista de Administración Pública, 194, 2014, pp. 275-316.

- SÁNCHEZ SOCÍAS, L., "Garantías del ciudadano frente a la Administración pública: panorama general”, en el vol. col. Gobierno y Administración en la Constitución, ed. Dirección General del Servicio Jurídico del Estado, vol. 2, 1988, pp. 17271786.

- SCHMIDT-ASSMANN, E., "La ciencia del Derecho administrativo ante el reto de la internacionalización de las relaciones administrativas", Revista de Administración Pública, 171, 2006, pp. 7-34.

- TORNOS MAS, J., Estudios sobre las Leyes 39/2015 del procedimiento administrativo común y 40/2015, del régimen jurídico del sector público, ed. Atelier, Madrid, 2017. 
- TORNOS MAS, J., "El principio de buena administración o el intento de dotar de alma a la Administración pública", en Derechos fundamentales y otros estudios en homenaje al Prof. D. Lorenzo Martín-Retortillo, Vol. I, ed. El Justicia de Aragón, Zaragoza, 2009, pp. 629-642.

- URIARTE RICOTE, M., "El derecho a una buena administración como garantía de un ejercicio de poder democrático", Carta de los Derechos Fundamentales de la Unión Europea y su reflejo en el ordenamiento jurídico español, ed. Thomson-Reuters Aranzadi, Cizur Menor, 2014, pp. 715-732. 